\title{
Pol5 is an essential ribosome biogenesis factor required for 605 ribosomal subunit maturation in Saccharomyces
} cerevisiae

\author{
ANA RAMOS-SÁENZ, ${ }^{1,2,7}$ DANIEL GONZÁLEZ-ÁLVAREZ, ${ }^{1,2,7}$ OLGA RODRÍGUEZ-GALÁN, , \\ ALFONSO RODRÍGUEZ-GIL, ${ }^{1}$ SONIA G. GASPAR, ${ }^{3,4}$ EDUARDO VILLALOBO, ${ }^{1,5}$ MERCEDES DOSIL, ${ }^{3,4,6}$ \\ and JESÚS DE LA CRUZ ${ }^{1,2}$ \\ ${ }^{1}$ Instituto de Biomedicina de Sevilla, Hospital Universitario Virgen del Rocío/CSIC/Universidad de Sevilla, E-41013, Seville, Spain \\ ${ }^{2}$ Departamento de Genética, Facultad de Biología, Universidad de Sevilla, E-41012, Seville, Spain \\ ${ }^{3}$ Centro de Investigación del Cáncer and Instituto de Biología Molecular y Celular del Cáncer, CSIC-Universidad de Salamanca, E-37007, \\ Salamanca, Spain \\ ${ }^{4}$ Centro de Investigación Biomédica en Red en Cáncer (CIBERONC), CSIC-Universidad de Salamanca, E-37007, Salamanca, Spain \\ ${ }^{5}$ Departamento de Microbiología, Facultad de Biología, Universidad de Sevilla, E-41012, Seville, Spain \\ ${ }^{6}$ Departamento de Bioquímica y Biología Molecular, Universidad de Salamanca, E-37007, Salamanca, Spain
}

\begin{abstract}
In Saccharomyces cerevisiae, more than 250 trans-acting factors are involved in the maturation of $40 \mathrm{~S}$ and $60 \mathrm{~S}$ ribosomal subunits. The expression of most of these factors is transcriptionally coregulated to ensure correct ribosome production under a wide variety of environmental and intracellular conditions. Here, we identified the essential nucleolar Pol5 protein as a novel trans-acting factor required for the synthesis of 605 ribosomal subunits. Pol5 weakly and/or transiently associates with early to medium pre-60S ribosomal particles. Depletion of and temperature-sensitive mutations in Pol5 result in a deficiency of 605 ribosomal subunits and accumulation of half-mer polysomes. Both processing of 27SB pre-rRNA to mature 25S rRNA and release of pre-60S ribosomal particles from the nucle(ol)us to the cytoplasm are impaired in the Pol5depleted strain. Moreover, we identified the genes encoding ribosomal proteins uL23 and eL27A as multicopy suppressors of the slow growth of a temperature-sensitive pol5 mutant. These results suggest that Pol5 could function in ensuring the correct folding of 25S rRNA domain III; thus, favoring the correct assembly of these two ribosomal proteins at their respective binding sites into medium pre-60S ribosomal particles. Pol5 is homologous to the human tumor suppressor Myb-binding protein 1A (MYBBP1A). However, expression of MYBBP1A failed to complement the lethal phenotype of a pol5 null mutant strain though interfered with $60 \mathrm{~S}$ ribosomal subunit biogenesis.
\end{abstract}

Keywords: ribosome biogenesis; pre-rRNA processing; MYBBP1A; ribosomal proteins uL23 and eL27; nucleolus

\section{INTRODUCTION}

Ribosomes are ubiquitous organelles that perform the translation of the mRNAs. In all organisms, ribosomes are composed of two ribosomal subunits (r-subunits), the large subunit being about twice the molecular mass of the small one. Both $r$-subunits are built from ribosomal RNAs (rRNAs) and ribosomal proteins (r-proteins). In the yeast Saccharomyces cerevisiae, the large or $60 \mathrm{~S} r$-subunit is composed of three rRNA species (25S, 5.8S, and 5S) and 46 r-proteins, whereas the small or $40 S$ r-subunit contains the 18S rRNA and 33 r-proteins (for reviews, see Melnikov et al. 2012; Wilson and Doudna Cate 2012). The complex

\footnotetext{
${ }^{7}$ These authors contributed equally to this work.

Corresponding authors: mdosil@usal.es, jdlcd@us.es

Article is online at http://www.rnajournal.org/cgi/doi/10.1261/rna. 072116.119 .
}

network of interactions connecting the rRNAs with the individual r-proteins and between rRNA segments or between different $r$-proteins has been revealed at atomic resolution by the crystal structures of the $80 \mathrm{~S}$ ribosome and the two r-subunits (for reviews, see Jenner et al. 2012; Klinge et al. 2012; Yusupova and Yusupov 2014).

The synthesis of ribosomes is a major cellular activity. In yeast, it has been estimated that more than 2000 ribosomes are produced per minute, thus, the content of an exponentially growing cell is about 200,000 ribosomes (Warner 1999). Due to the huge investment of resources

\footnotetext{
(C) 2019 Ramos-Sáenz et al. This article is distributed exclusively by the RNA Society for the first 12 months after the full-issue publication date (see http://rnajournal.cshlp.org/site/misc/terms.xhtml). After 12 months, it is available under a Creative Commons License (Attribution-NonCommercial 4.0 International), as described at http:// creativecommons.org/licenses/by-nc/4.0/.
} 
devoted to ribosome production, ribosome biogenesis is a tightly regulated process that involves the coordinated maturation of the precursors rRNAs (pre-rRNAs) and their concomitant assembly together with the r-proteins (for reviews, see Fromont-Racine et al. 2003; Woolford and Baserga 2013; Kressler et al. 2017). Biogenesis of ribosomes is also a highly dynamic process, taking place both in the nuclear and cytoplasmic cellular compartments. In the yeast nucleolus, about half of the 100-200 tandem rDNA copies are transcribed as two primary transcript units; the large one, which is synthesized by RNA polymerase I (RNAP I), encompasses the mature sequences of $18 \mathrm{~S}, 5.8 \mathrm{~S}$, and $25 \mathrm{~S}$ rRNAs, while the precursor of $5 \mathrm{~S}$ is independently transcribed by RNAP III. Maturation of rRNAs is a well-defined pathway (Supplemental Fig. S1) and involves processing and covalent rRNA modification reactions (for review, see Fernández-Pevida et al. 2015). Pre-rRNA maturation takes place inside preribosomal particles, which are formed by the association of many transacting assembly factors with the pre-rRNAs and the r-proteins (for reviews, see Woolford and Baserga 2013; Kressler et al. 2017). The latter ones assemble in a hierarchical manner; thus, distinct r-proteins, called primary binding proteins, stably bind directly to the nascent prerRNAs, while secondary and ternary binding proteins associate later and always after the previous binding of one or more primary r-proteins; the last r-proteins assemble in the cytoplasm (for review, see de la Cruz et al. 2015). Trans-acting factors transiently bind to the particles in a distinctive spatiotemporal manner and ensure the speed, directionality and accuracy of ribosome biogenesis, as they perform specific functions not only during the maturation of the pre-rRNAs but also during the progressive folding of the pre-rRNAs, the assembly of the r-proteins, the acquisition of nuclear export competence, nuclear export, and the final cytoplasmic maturation steps of the preribosomal particles to mature r-subunits (Kressler et al. 1999, 2010, 2017; Venema and Tollervey 1999; Woolford and Baserga 2013; Nerurkar et al. 2015; Peña et al. 2017; Bassler and Hurt 2019). The purification of preribosomal particles by in vivo affinity-purification methods has allowed the isolation, characterization and compositional analysis of several intermediates along the ribosome maturation pathway (for reviews, see Fromont-Racine et al. 2003; Kressler et al. 2010; Woolford and Baserga 2013; Bassler and Hurt 2019). More recently, progress in cryo-electron microscopy (cryo-EM) has revealed the structure at a near-atomic resolution of some of these affinity-purified preribosomal particles, including the precise localization of the trans-acting factors that are stably associated with them (for reviews, see Bassler and Hurt 2019; Klinge and Woolford 2019). More importantly, the structures of different particles along the r-subunit assembly pathway provide insights into how trans-acting factors, pre-rRNAs, and r-proteins mechanistically participate during the rearrangements and remodeling events of preribosomal particles throughout their subsequent maturation steps (for reviews, see Konikkat and Woolford 2017; Kressler et al. 2017; Peña et al. 2017; Barandun et al. 2018; Bassler and Hurt 2019; Klinge and Woolford 2019).

Practically all protein trans-acting factors involved in ribosome biogenesis, more than 250, have been identified and functionally characterized in yeast. A large number of these factors were identified by classical and modern molecular genetics, including the systematic functional analysis of yeast open reading frames, or a consequence of being nucleolar proteins (e.g., see Kressler et al. 1999; Venema and Tollervey 1999; Henras et al. 2008). Many other factors were identified as components of affinity-purified preribosomal particles either isolated by specific or high-throughput approaches (e.g., see Bassler et al. 2001; Harnpicharnchai et al. 2001; Grandi et al. 2002; Nissan et al. 2002; Schäfer et al. 2003; Gavin et al. 2006). Additional factors have been described as the result of integrative and predictive approaches for identifying sets of coregulated genes, as they belong to the so-called "rRNA and ribosome biosynthesis" (RRB) regulon, also known as the "ribosome biogenesis" (RiBi) regulon (Wade et al. 2001, 2006; Jorgensen et al. 2004), by computational network-guided genetics (Li et al. 2009) or directly by studying the pre-rRNA processing defects of yeast mutants by a microarray study (Peng et al. 2003). Nowadays, new trans-acting factors are still being discovered as typified by the dedicated chaperones for r-proteins (Pillet et al. 2017).

In this work, we functionally characterize the protein Pol5 (YEL055Cp), thereby, revealing that it plays a role in ribosome biogenesis. Pol5 was initially identified as an essential nucleolar protein, which harbors a DNA polymerase activity in vitro that is fully dispensable in vivo (Shimizu et al. 2002). Instead of being required for DNA replication, it has been suggested that Pol5 is required for transcription of the large pre-rRNA by RNAP I (Shimizu et al. 2002). Consistently, Pol5 weakly copurifies with the so-called UtpA/t-UTP subcomplex (Gallagher et al. 2004; Krogan et al. 2004), which is believed to be the protein module that binds first to the large pre-rRNA during the formation of early 905 preribosomal particles. UtpA association to the large pre-rRNA seems to occur cotranscriptionally and this is required for both efficient pre-rRNA transcription and recruitment of other subcomplexes to these nascent particles (Gallagher et al. 2004; Pérez-Fernández et al. 2007, 2011; Chaker-Margot et al. 2015; Zhang et al. 2016; Gallagher 2019). Our data, however, indicate that Pol5 is an RRB/RiBi factor required for maturation of $60 \mathrm{~S}$ r-subunits. Thermosensitive (ts) pol5 mutations and depletion of Pol5 result in a $60 \mathrm{~S}$ r-subunit shortage that is due to both defective $27 \mathrm{~S}$ pre-rRNA processing leading to reduced levels of 25S mature rRNAs and impairment of nuclear export of pre-60S r-particles. In agreement with 
these phenotypes, affinity purification of a fully functional GFP-tagged Pol5 construct yields mainly 27SB pre-RNAs, therefore, suggesting that Pol5 associates with early/medium pre-60S r-particles. In addition, we also show that overexpression of specific 60S r-proteins (uL23 and eL27A) suppresses the growth defect of selected ts pol5 mutants. Strikingly, Pol5 shares some similarity to mammalian Mybbinding protein 1A (MYBBP1A), which is a tumor suppressor that represses the activity of selected transcription factors involved in the control of several relevant biological processes such as cellular division, proliferation and apoptosis (e.g., Mori et al. 2012; Felipe-Abrio et al. 2019). MYBBP1A, as Pol5, also participates in rRNA transcription by RNAP I and pre-rRNA processing reactions in the pathway for mature 28S/5.8S rRNA production (Hochstatter et al. 2012; Tafforeau et al. 2013). However, whether Pol5 and MYBBP1A are functional orthologs is still unclear; in this regard, our data show that human MYBBP1A cannot complement a yeast pol5 null mutant strain.

\section{RESULTS}

\section{Pol5 is a member of the $\mathrm{RRB} / \mathrm{RiBi}$ regulon}

Genes encoding proteins involved in different aspects of yeast RNA metabolism are known to have similar transcrip- tion patterns in cells progressing through different physiological programs (e.g., cell cycle, sporulation, and diauxie) or subjected to a variety of insults (e.g., osmotic or heat shock stresses, and drug treatments such as rapamycin) (Causton et al. 2001; Wade et al. 2001, 2006; Jorgensen et al. 2004). Collectively, all these genes ( 250) are classified as members of the RRB/RiBi regulon, which does not include any of the 138 r-protein genes (for reviews, see Broach 2012; Bosio et al. 2017). Despite its possible role in ribosome biogenesis (see Introduction), POL5 was not ranked among the best approximately 200 genes belonging to the RRB/RiBi regulon and was described as lacking RRPE and PAC consensus sequences in its promoter (see Jorgensen et al. 2004; Wade et al. 2006). These elements are characteristic of the promoter regions of the RRB/RiBi genes. They are located at positions between 50 and 200 bp upstream of their respective translational start sites and play a role in their transcriptional regulation (for reviews, see Bosio et al. 2011, 2017). To determine whether the expression of POL5 is coregulated with that of bonafide members of the RRB/RiBi regulon, we performed two independent analyses: (i) first, we checked for RRPE and $P A C$ consensus sequences within the promoter region of POL5. As depicted in Figure 1A, the POL5 promoter indeed contains a degenerate RRPE box in the $-150 \mathrm{bp}$ position with only one deviation in its first nucleotide

A

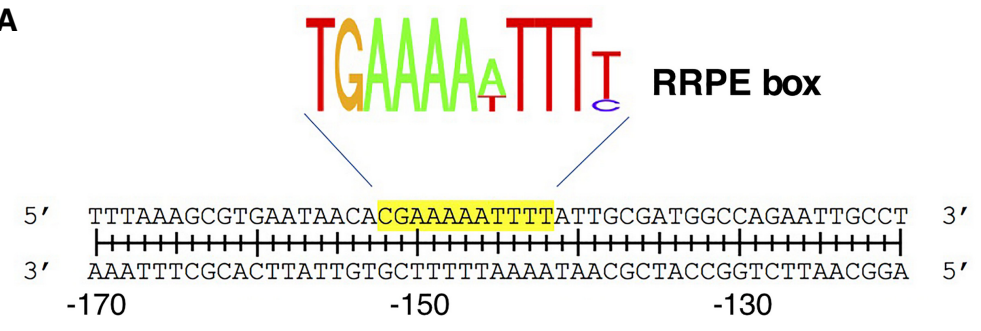

B
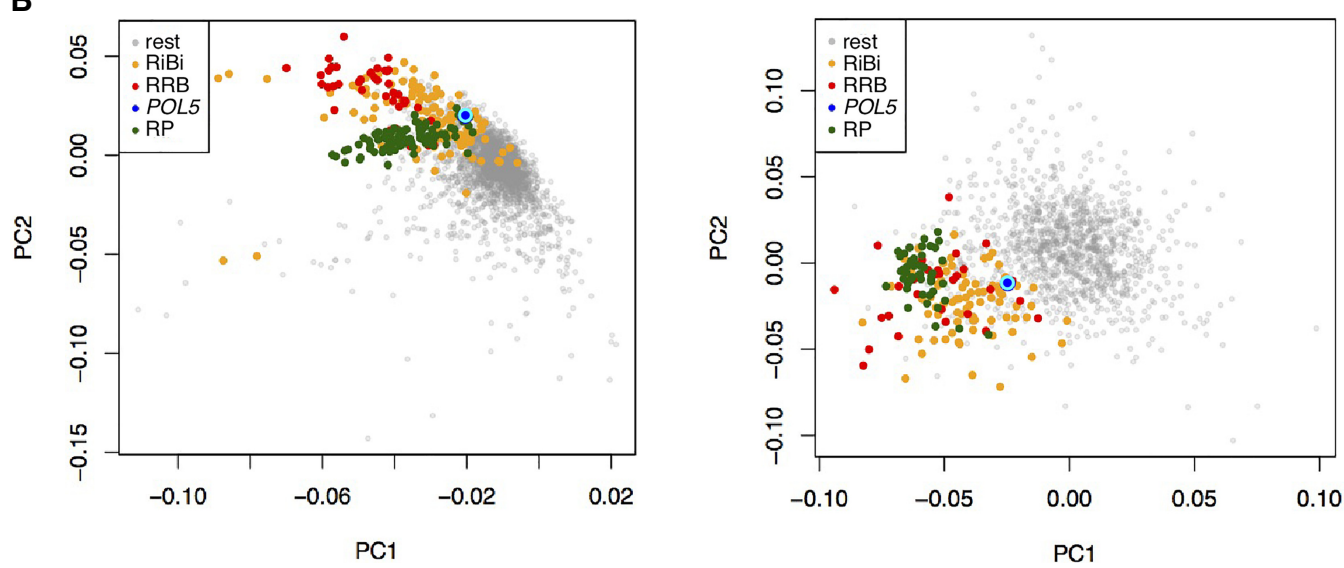

FIGURE 1. Pol5 is a member of the RRB/RiBi regulon. (A) The promoter of POL5 contains a degenerate RRPE motif, which deviates from the consensus sequence only at the first position. As shown, the element is positioned between base pairs -152 and -142 upstream with respect to the translation start codon. (B) POL5 expression is coregulated with that of RRB/RiBi genes. PCA plots at left: the four data sets studied in Wade et al. (2006) combined as a single data set; right, the expression data described in Jorgensen et al. (2002). The first ( $x$-axis, PC1) and second (y-axis, PC2) principal components are shown. Colors were assigned to RRB, RiBi, r-protein (RP) genes, POL5, and the rest of yeast genes. 
( $C$ instead of $T$ ) compared with the RRPE consensus sequence. However, the POL5 promoter apparently lacks a PAC sequence element (but see Discussion). (ii) Second, we performed a principal component analysis (PCA) of the four gene expression profile data sets used in the original analyses of Wade et al. (2001, 2006), where the RRB genes were defined as transcriptionally coregulated. These data sets correspond to cell-cycle synchronized cells by $\alpha$-factor arrest and release, cells entering the sporulation pathway, and cells subjected to heat shock or osmotic stress. As shown in Figure 1B, POL5 expression is clearly grouped within that of RRB genes. We also extended this PCA to the data set used by Jorgensen et al. (2004) to define the RiBi regulon. As above, POL5 expression mapped within that of the bulk of the RiBi genes (Fig. 1B). Together, these findings suggest that Pol5 belongs to the $\mathrm{RRB} / \mathrm{RiBi}$ regulon as it contains an almost perfect RRPE box and exhibits expression profiles similar to those of the RRB/RiBi cluster members.

\section{Strains for the phenotypic analysis of Pol5}

Pol5 is essential for cell viability (Winzeler et al. 1999; Shimizu et al. 2002); thus, to study its role in ribosome biogenesis, we made use of two different conditional systems. First, we generated a conditional GAL::HA-POL5 allele at the POL5 genomic locus by one-step insertion of a kanMX6-GAL1/10::HA cassette upstream of its start codon. The resulting construct expresses an amino-terminally HA-tagged Pol5 fusion protein in media containing galactose but is repressed in media containing glucose. Growth of the GAL::HA-POL5 strain was identical to that of the isogenic wild-type strain on YPGal plates, indicating that the allele is fully functional; however, it did not permit growth on YPD plates (Supplemental Fig. S2A). After transfer of the GAL::HA-POL5 strain from liquid YPGal to liquid YPD medium, the growth rate remained similar to that of the wild-type strain for the first $6 \mathrm{~h}$ but then progressively decreased to a doubling time of $>10 \mathrm{~h}$ after $12 \mathrm{~h}$ in YPD medium. Concomitantly, GAL::HA-POL5 cells were depleted of the HA-Pol5 protein, as revealed by western blot analysis (Supplemental Fig. S2B).

As a second conditional system for phenotypic analysis, we used the previously described pol5-1 and pol5-3 ts mutants (Shimizu et al. 2002; Li et al. 2011). The pol5-1 mutant showed apparent wild-type growth on YPD plates at $25^{\circ} \mathrm{C}$ but a marked slow growth (sg) at $37^{\circ} \mathrm{C}$. In turn, the pol5-3 mutant showed a mild sg at $25^{\circ} \mathrm{C}$ but a severe ts growth at $37^{\circ} \mathrm{C}$ (Supplemental Fig. S3). In liquid YPD medium, the pol5-1 mutant and the isogenic wild-type strain showed doubling times of $\sim 2.0 \mathrm{~h}$ at $25^{\circ} \mathrm{C}$, while that for pol5-3 mutant was of $\sim 3 \mathrm{~h}$. After $12 \mathrm{~h}$ at $37^{\circ} \mathrm{C}$, the doubling times were of $\sim 7$ and $13 \mathrm{~h}$ for the pol5-1 and the pol5-3 mutant, respectively, compared with the $\sim 1.7 \mathrm{~h}$ for the isogenic wild-type strain. The mutations within the pol5-1 and pol5-3 alleles lead to specific amino acid substitutions (V404M, K491E and Q671P for Pol5-1; W292R for Pol53); however, the molecular significance of the amino acid changes with respect to the ts phenotype of the respective mutants has not been determined (Shimizu et al. 2002; Li et al. 2011). Moreover, these mutations are recessive since the transformation of the pol5-1 and the pol5-3 mutants with YCplac111-POL5, a centromeric plasmid harboring a wild-type POL5 allele, restored wild-type growth (see below Supplemental Fig. S10). Additionally, we used the pol5dn mutant, which encodes a Pol5[D623N;D625N] protein variant that lacks DNA polymerase activity in vitro (Shimizu et al. 2002). As also shown in Supplemental Figure S3, this mutant did not display any growth defect on YPD plates at any of the tested temperatures. In liquid YPD medium, it exhibited wild-type growth with a doubling time of $\sim 2.0 \mathrm{~h}$ at $25^{\circ} \mathrm{C}$.

Finally, we also used a strain expressing carboxy-terminally GFP-tagged Pol5 from its genomic locus as the sole source of Pol5. This construct was obtained by a onestep insertion of a PCR-derived cassette. As shown in Supplemental Figure S4A, no growth impairment was seen for this strain in YPD plates, indicating that the fusion construct is functional. Moreover, the fusion protein could be detected by western blot analysis using anti-GFP antibodies as a single band of the expected molecular mass of 143 kDa (Supplemental Fig. S4B).

\section{Pol5 associates with pre-60S ribosomal particles}

To start addressing the possible role of Pol5 in ribosome biogenesis, we determined whether a GFP-tagged Pol5 protein interacts with preribosomal particles. As stated above, this fusion protein sustains wild-type growth when it is the only source of cellular Pol5. In addition, the strain expressing Pol5-GFP showed wild-type polysome profiles, including normal levels of free 40S and 60S r-subunits (Supplemental Fig. S4C). The Pol5-GFP protein was predominantly found in the nucleolus, where it colocalized with a DsRed-Nop1 reporter (Supplemental Fig. S5). This result agrees with that of Shimizu et al. (2002), who reported that a 9xMyc-tagged Pol5 construct was restricted to the nucleolus.

To test whether Pol5 associates with r-particles, we affinity-purified Pol5-GFP containing complexes with GFP-Trap beads and analyzed which pre-rRNAs species were copurifying by northern blot hybridization (see Supplemental Fig. S1 for a scheme of pre-rRNA species). As shown in Figure 2, the $27 \mathrm{SA}_{2}$ and the 27SB pre-rRNAs were clearly enriched in the Pol5-GFP purification compared with the control purification performed with cell extracts derived from the isogenic wild-type strain expressing untagged Pol5. Very minor amounts of the 35S and 32S pre-rRNAs appear to also copurify with Pol5-GFP. However, neither $7 \mathrm{~S}$ or $20 \mathrm{~S}$ pre-rRNAs nor mature rRNAs were detected 


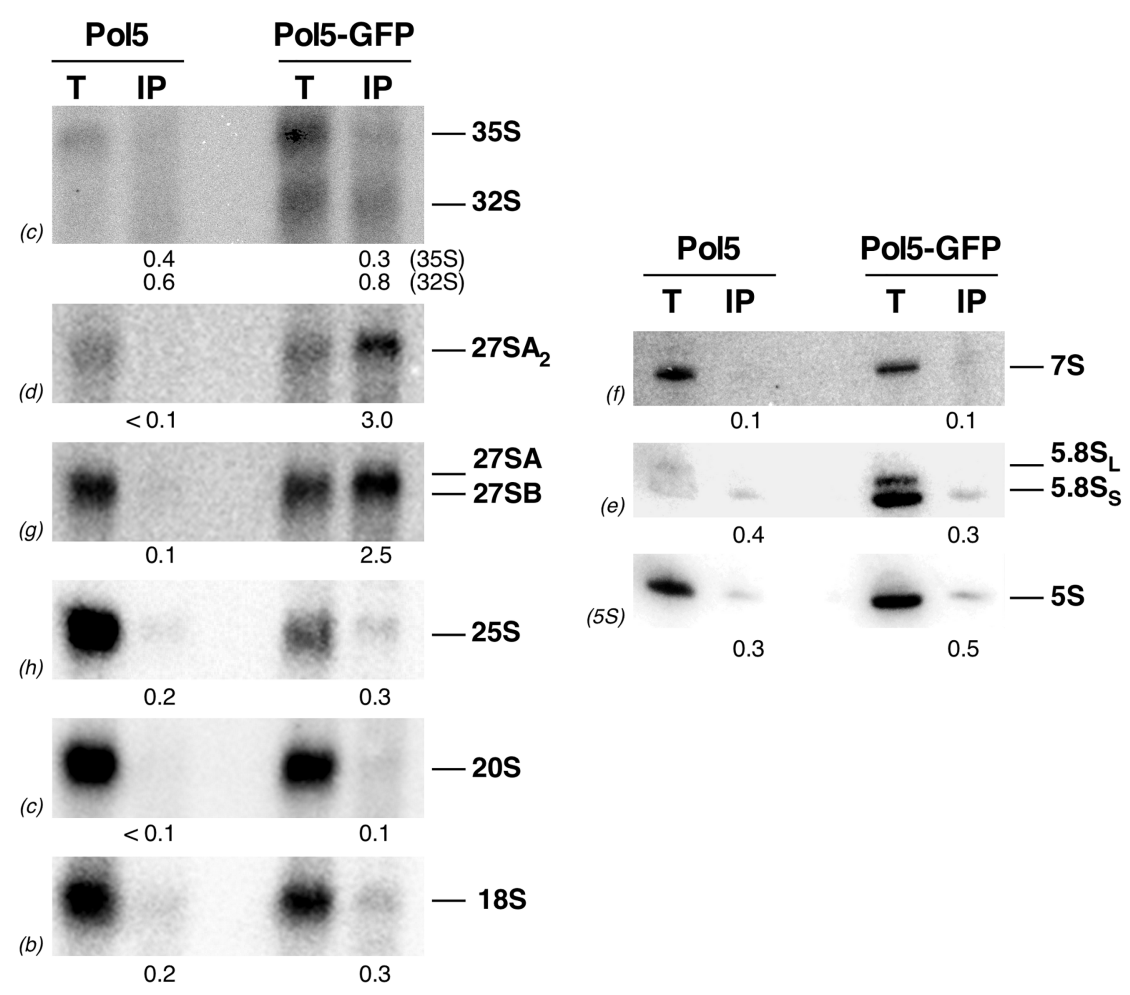

FIGURE 2. Pol5 is associated with pre-60S r-particles. Association of pre- and mature rRNAs with Pol5 was revealed by the GFP-Trap immunoprecipitation procedure with cell extracts of strain YMP1, which expresses the Pol5-GFP fusion protein as the sole source of cellular Pol5. Wild-type cells (untagged Pol5) were used as negative control. Cells were grown in YPD at $30^{\circ} \mathrm{C}$ to an $\mathrm{OD}_{600}$ of approximately 0.8 and harvested. Total RNA was extracted from whole cell extracts $(T)$ and immunoprecipitates (IP) and pre-rRNAs present were analyzed by northern blotting using the probes indicated between parentheses (see Supplemental Table S3 for their sequence and Supplemental Figure S1 for their location within 35 S pre-rRNA). Signal intensities were measured by phosphorimager scanning; values (below each IP lane) refer to the percentage of each RNA species recovered after purification relative to the total extract input.

units and, accordingly, half-mer polysomes could be observed (Fig. 3). These features were even more pronounced upon a longer shift of $8 \mathrm{~h}$ to YPD (data not shown). The specific shortage of 605 r-subunits upon depletion of Pol5 was further confirmed by quantification of total r-subunits in low $\mathrm{Mg}^{2+}$ sucrose gradients; thus, an $\mathrm{A}_{254} 60 \mathrm{~S} / 40 \mathrm{~S}$ ratio of approximately 1.8 was calculated for the GAL::HA-POL5 strain grown in YPGal medium and for the isogenic wildtype counterpart grown in YPGal or YPD medium, while this ratio decreased to approximately 1.1 after transfer of the GAL::HA-POL5 strain to YPD for $8 \mathrm{~h}$ (Supplemental Fig. S6).

Polysome analyses were also performed with cell extracts prepared from the pol5-1 and pol5-3 mutant and the isogenic wild-type strain grown in YPD at the permissive temperature of $25^{\circ} \mathrm{C}$ or $6 \mathrm{~h}$ after a shift to the nonpermissive temperature of $37^{\circ} \mathrm{C}$. As shown in Supplemental Figure S7A, the pol5-1 and pol5-3 mutations also led to a significant shortage of 60S r-subunits after the temperature shift, as revealed by the deficit of free 605 versus 405 r-subunits and the appearance of half-mer polysomes. These defects were rescued by complementation of the mu-

above the background levels obtained for these species in the control purification from the untagged strain (Fig. 2). Altogether, these data indicate that Pol5 is a component of early/medium nucleolar pre-60S r-particles. Pol5 apparently associates with particles at an early stage during formation of $27 \mathrm{SA}_{2}$ pre-rRNA and dissociates from nucle(ol)ar particles after 27SB pre-rRNA cleavage but before their nuclear export to the cytoplasm.

\section{Pol5 is required for 605 ribosomal subunit accumulation}

The association of Pol5 with pre-60S r-particles suggests its participation in $60 \mathrm{~S}$ r-subunit maturation. To investigate this, we studied the consequences of the loss-of-function of Pol5 on ribosome metabolism. We first examined the polysome profiles of the GAL::HA-POL5 strain grown in YPGal medium or subjected to Pol5 depletion by a shift to YPD medium. In YPGal, the strain showed a normal polysome profile (Fig. 3). However, when shifted for only $3 \mathrm{~h}$ to YPD, there was a deficit in free $60 \mathrm{~S}$ versus free $40 \mathrm{~S} r$-sub- tants with a plasmid harboring the wild-type POL5 gene (see later Supplemental Fig. S11 for pol5-1; not shown for pol5-3). Finally, we also analyzed polysome profiles from extracts of pol5dn cells grown in YPD at $30^{\circ} \mathrm{C}$. In this case, the profiles were identical to those of wild-type cells (Supplemental Fig. S7B). Taken together, these results indicate that Pol5 is required for normal $60 \mathrm{~S} r$-subunit accumulation; however, its presumed DNA polymerase activity appears to be dispensable for its role in ribosome biogenesis.

\section{Pol5 is required for pre-rRNA processing}

To discern whether the 60S r-subunit shortage occurring in conditional pol5 strains is accompanied by defects in prerRNA processing, we analyzed the effects of Pol5 depletion on steady-state levels of pre- and mature rRNAs by northern hybridization and primer extension. As shown in Figure 4A, depletion of Pol5 resulted in a decrease of mature $25 \mathrm{~S}$ rRNA but not of $18 \mathrm{~S}$ rRNA. There was a clear accumulation of the $35 \mathrm{~S}$ pre-rRNA, which was accompanied by 


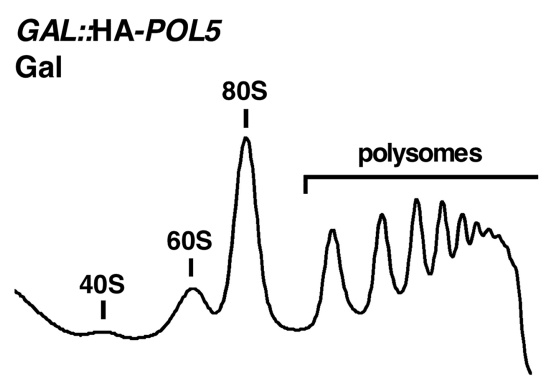

GAL:HA-POL5
Glc $3 \mathrm{~h}$

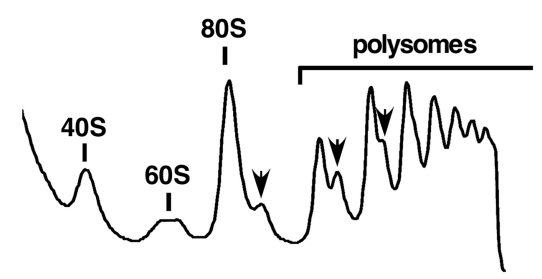

FIGURE 3. Depletion of Pol5 results in a $60 \mathrm{~S} r$-subunit shortage. YJP38 (GAL::HA-POL5) cells were grown in liquid YPGal medium (Gal) and shifted to YPD (Glc) for $3 \mathrm{~h}$. Cells were harvested at an $\mathrm{OD}_{600}$ of approximately 0.8 , total cell extracts were prepared and $10 A_{260}$ units of each extract were resolved in standard $7 \%-50 \%$ sucrose gradients. The $A_{254}$ was continuously measured. Sedimentation is from left to right. The peaks of free $40 \mathrm{~S}$ and $60 \mathrm{~S}$ r-subunits, vacant $80 \mathrm{~S}$ ribosomes or monosomes and polysomes are indicated. Half-mers are labeled by arrows.

the appearance of an aberrant $23 \mathrm{~S}$ species. Consistently, there was some alteration in the levels of $27 \mathrm{SA}_{2}$ and $20 \mathrm{~S}$ pre-rRNAs. Importantly, a clear increase in the levels of 27SB pre-rRNAs was observed upon depletion of Pol5. Regarding low-molecular-mass rRNAs, depletion of Pol5 resulted in a very minor alteration in the accumulation of mature 5.8S rRNAs and no apparent change in the levels of the $5 \mathrm{~S}$ rRNA or the ratios between $5.8 \mathrm{~S}_{\mathrm{L}}$ and $5.8 \mathrm{~S}_{\mathrm{S}}$ rRNAs (Fig. 4B). Nevertheless, it has been previously shown that these small mature rRNAs are more stable than $25 \mathrm{~S}$ and 18S rRNA and depleted more slowly (e.g., Kressler et al. 1998; Thomson and Tollervey 2005). Similarly, the levels of 7S pre-rRNAs were neither clearly decreased upon Pol5 depletion, although they did not achieve the levels detected in the wild-type strain.

Primer extension analyses were performed using a probe hybridizing within the region $\mathrm{C}_{1}-\mathrm{C}_{2}$ of ITS2 (probe g; see Supplemental Table S3; Supplemental Fig. S1). Consistent with the northern blot results, minor differences in the primer extension stop at site $A_{2}$ but a significant increase in those at sites $B_{1 L}$ and $B_{1 S}$ were observed upon depletion of Pol5 (Fig. 4C). Levels of the $27 \mathrm{SA}_{3}$ prerRNA, which cannot be readily detected in northern blots, modestly increased upon depletion of Pol5 as shown by the stop at site $A_{3}$ (Fig. 4C). Finally, a slight decrease in the levels of the $25.5 \mathrm{~S}$ pre-rRNA was detected following Pol5 depletion.

Together, these data demonstrate that Pol5 is required for proper ITS2 processing. Thus, depletion of Pol5 impairs processing of $27 \mathrm{~S}$ pre-rRNAs, which is the likely cause of the reduced production of mature $60 \mathrm{~S}$ r-subunits. As occurring for many mutants affecting 60S r-subunit synthesis (for review, see Fernández-Pevida et al. 2015), processing at the early $A_{0}-A_{2}$ sites is also modestly impaired.

\section{Depletion of Pol5 impairs nucleo-cytoplasmic transport of pre-60S r-particles}

It has been well reported that diverse failures along the ribosome assembly pathway lead to the nucle(ol)ar retention of immature and/or defective preribosomal particles and hence to the impairment of their export to the cytoplasm (e.g., Fatica et al. 2003; Milkereit et al. 2003; Ferreira-Cerca et al. 2005; Pöll et al. 2009). In only a few particular cases, immature preribosomal particles gain export competence and are able to exit to the cytoplasm, where they may even be able to engage in translation (e.g.,Kressler et al. 2008; Ferreira-Cerca et al. 2014; Rodríguez-Galán et al. 2015; Sarkar et al. 2017). Thus, to determine whether Pol5 depletion impairs nuclear export of pre-60S r-particles, we assessed the intracellular localization of the reporter uL23-eGFP (formerly L25-eGFP) in the GAL::HA-POL5 strain either grown in selective SGal medium or after a shift of $9 \mathrm{~h}$ to selective SD medium. As expected for an r-protein, uL23-eGFP was found in the cytoplasm of practically all cells when grown in liquid SGal medium (Supplemental Fig. S8A). However, following the shift to selective SD medium, uL23-eGFP accumulated in the nucle(ol)us as revealed by the colocalization with the nucleolar marker DsRed-Nop1 (Supplemental Fig. S8A). No nuclear accumulation of the uL23-eGFP reporter was observed when an isogenic POL5 wild-type strain was analyzed in identical growth conditions (Supplemental Fig. S9A). Moreover, the 40S r-subunit reporter uS3-eGFP did not show nuclear retention in neither the GAL::HA-POL5 nor the POL5 strains when grown in liquid SGal medium or shifted up to $9 \mathrm{~h}$ to SD medium (Supplemental Figs. S8A, S9A). Pol5 functionally interacts with uL23 (see below). Thus, to exclude the possibility that the nucle(ol)ar accumulation of uL23-eGFP observed upon Pol5 depletion could be due to a specific failure of its assembly rather than to an impairment of nucleo-cytoplasmic export of defective pre-60S ribosomal particles, we also monitored the intracellular localization of two additional $60 \mathrm{~S}$ r-subunit reporters, eL22A-eGFP and uL5-eGFP. The results with these reporters were identical to those with uL23-eGFP (Supplemental Figs. S8B, S9B). Taken together, these experiments indicate that both the intra-nuclear and nucleocytoplasmic transport of pre-60S r-particles is impaired upon Pol5 depletion. 
A

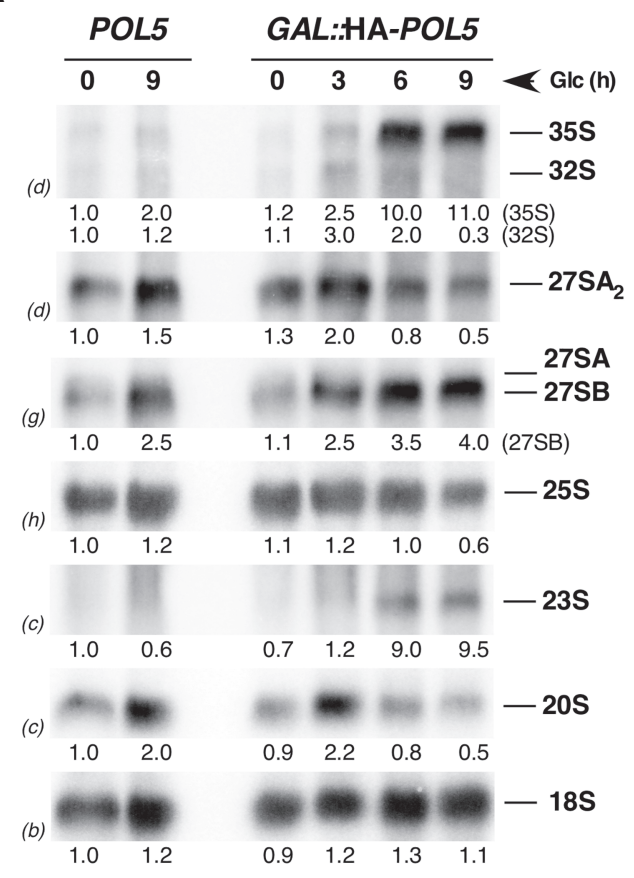

B

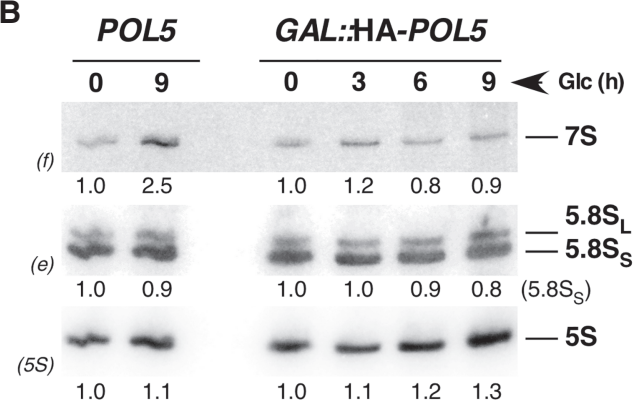

C

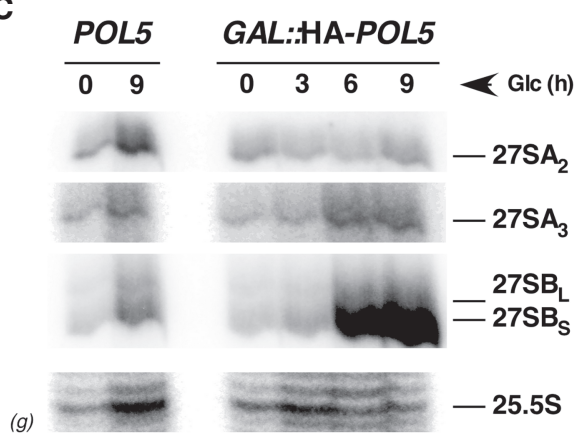

FIGURE 4. Depletion of Pol5 impairs pre-rRNA processing. Strains W303-1B (POL5) and YJP38 (GAL::HA-POL5) were grown at $30^{\circ} \mathrm{C}$ in liquid YPGal medium and shifted to YPD. Cells were maintained in exponential growth throughout the time course of the experiment by culture dilution with the prewarmed medium. Total RNA was extracted from the cultures at the indicated times after the shift, and equal amounts $(5 \mu \mathrm{g})$ were subjected to northern hybridization or primer extension analyses. (A) Northern blot analysis of high-molecular-mass and (B) low-molecularmass pre- and mature rRNAs. Probes, between parentheses, are described in Supplemental Table S3 and Supplemental Figure S1. Signal intensities were measured by phosphorimager scanning; values (below each lane) were normalized to those obtained for the wild-type control grown in YPGal, arbitrarily set at 1.0. (C) Primer extension analysis using an oligonucleotide that hybridizes within the $C_{1}-C_{2}$ region of ITS2 (probe g), thereby allowing detection of the $25.5 \mathrm{~S}, 27 \mathrm{SA}_{2}$, and $27 \mathrm{SA}_{3}$ pre-rRNAs as well as both $27 \mathrm{SB}$ pre-rRNA species.

\section{Overexpression of uL23 and eL27A r-proteins suppresses the thermosensitive phenotype of the pol5-1 mutant}

To better understand the function of Pol5, we carried out a screen for multicopy suppressors of the ts phenotype of the pol5-1 mutant. This mutant was transformed with a YEplac181-based multicopy library (de la Cruz et al. $1997)$, and the transformants $(\sim 35,000)$ were incubated for $5 \mathrm{~d}$ at the nonpermissive temperature $\left(37^{\circ} \mathrm{C}\right)$. Plasmid DNA was isolated from the thermo-tolerant candidates, rescued in Escherichia coli, and back-transformed into the original pol5-1 mutant. Four plasmids were able to reproducibly suppress the growth defect of the mutant at $37^{\circ} \mathrm{C}$. One contained the wild-type POL5 gene, two others harbored the RPL27A gene and the last one the RPL25 gene. Further cloning of the PCR-amplified RPL27A and RPL25 genes into YEplac181 or YEplac195, and subsequent transformation of these plasmids into the po/5-1 mutant confirmed that these two 60S r-protein genes indeed confer the multicopy suppression (Fig. 5; Supplemental Fig. S10). To further test the allele specificity of the suppressor effect, we also transformed the POL5 shuffle and the pol5-3 strains with the RPL25- and RPL27A-containing multicopy plasmids. While increased gene dosage of neither RPL25 nor RPL27A could overcome the essential function of Pol5 at $30^{\circ} \mathrm{C}$ (data not shown), overexpression of eL27A (formerly L27A) also suppressed the growth defect of pol5-3 mutant cells to practically the wild-type extent at $37^{\circ} \mathrm{C}$ (Fig. 5; Supplemental Fig. S10). In addition, we also cotransformed the pol5 ts mutants with multicopy plasmids harboring RPL25 and RPL27A. Interestingly, simultaneous overexpression of uL23 (formerly L25) and eL27A resulted in better suppression of the growth defect of the pol5-1 mutant at $37^{\circ} \mathrm{C}$ than the individual overexpression of each r-protein alone (Fig. 5). These results strongly suggest that the function of Pol 5 during $60 \mathrm{~S} \mathrm{r}$-subunit biogenesis could be related to that of $60 \mathrm{~S}$ r-proteins uL23 and eL27A. To test whether overexpression of these r-proteins restored $60 \mathrm{~S}$ r-subunit synthesis in the conditional pol5 mutants, we performed polysome profile analysis. However, increased dosage of neither RPL25 nor of RPL27A alone resulted in a significant improvement of the 60S r-subunit shortage detected in the pol5 mutants and only co-overexpression of UL23 and eL27A minorly improves polysome formation in the suppressed pol5-1 strain 


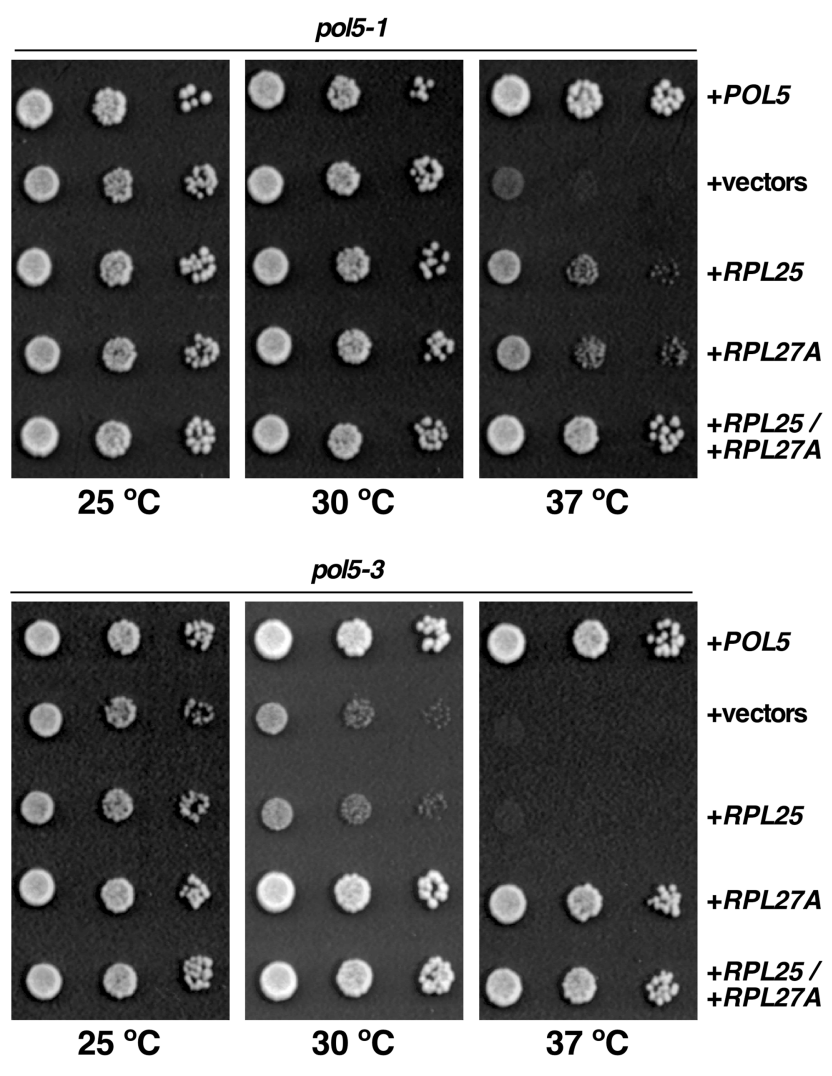

FIGURE 5. Suppression of the growth defects of selected pol5 mutants by high-dosage of uL23 and eL27A. Strains Y10143 (pol5-1) and Y10144 (pol5-3) were transformed with the following combination of plasmids: YCplac111-POL5 and YCplac33 (+POL5), multicopy plasmids YEplac181 and YEplac195 (+vectors), YEplac181-RPL25 and YEplac195 (+RPL25), YEplac181 and YEplac195-RPL27A (+RPL27A), and YEplac181-RPL25 and YEplac195-RPL27A (+RPL25/+RPL27A). Transformants were grown in liquid SD-Leu-Ura medium and diluted to an $\mathrm{OD}_{600}$ of 0.05 . Serial 10-fold dilutions were spotted onto SDLeu-Ura plates, which were incubated at $25^{\circ} \mathrm{C}, 30^{\circ} \mathrm{C}$, and $37^{\circ} \mathrm{C}$ for $3 \mathrm{~d}$. Note that co-overexpression of uL23 and eL27A suppresses the ts phenotype of the pol5-1 mutant better than single overexpression of $\mathrm{UL} 23$ or eL27A.

grown at $37^{\circ} \mathrm{C}$ (Supplemental Fig. S11 for pol5-1; data not shown for pol5-3). Consistently, quantification of total $r$ subunits in low $\mathrm{Mg}^{2+}$ sucrose gradients confirmed a comparable reduction of approximately $30 \%$ in the overall amount of $60 \mathrm{~S}$ r-subunits in the pol5-1 mutant transformed either with an empty vector or the multicopy plasmids harboring RPL25 or RPL27A, grown in SD-Leu at $30^{\circ} \mathrm{C}$ and then transferred for $9 \mathrm{~h}$ to $37^{\circ} \mathrm{C}\left(\mathrm{A}_{254} 60 \mathrm{~S} / 40 \mathrm{~S}\right.$ ratio of 1.3), relative to the pol5-1 strain complemented with a plasmid harboring a wild-type POL5 gene or an isogenic wild-type strain $\left(\mathrm{A}_{254} 60 \mathrm{~S} / 40 \mathrm{~S}\right.$ ratio of 1.8) (Supplemental Figs. S6, S12). This reduction was clearly lower ( 15\%) in the pol5-1 mutant cotransformed with multicopy plasmids harboring RPL25 and RPL27A ( $\mathrm{A}_{254} 60 \mathrm{~S} / 40 \mathrm{~S}$ ratio of 1.5$)$ (Supplemental Fig. S12). Altogether, these results suggest that higher levels of uL23 and/or eL27A in pol5 mutants might qualitatively ameliorate ribosome production or function as we did not observe any marked increase in the absolute levels of mature r-subunits in the suppressed strains compared with the original pol5 mutants.

\section{Expression of an HA-MYBBP1A construct exerts a negative effect on growth and 605 r-subunit production}

Yeast Pol5 and mammalian MYBBP1A are predicted to be orthologs (Yang et al. 2003). Moreover, similarly to Pol5, MYBBP1A may have a role in ribosome biogenesis (Hochstatter et al. 2012; Tafforeau et al. 2013). Hence, we wondered whether these proteins are also functionally equivalent and can complement each other. To test this possibility, we studied the ability of the major isoform of human MYBBP1AcDNA to rescue the lethal phenotype of the pol5 null mutant. This isoform, called p160 since it corresponds to the full-length $160 \mathrm{kDa}$ nucleolar variant of MYBBP1A (Tavner et al. 1998), was amino terminally HAtagged and the construct expressed from the strong yeast GAL1-10 promoter in the POL5 shuffle strain. As shown in Supplemental Figure S13A, expression of HA-MYBBP1A exerted a severe negative effect on the growth of this strain. Moreover, when the plasmid harboring the wild-type POL5 allele was shuffled on 5-FOA plates containing galactose as carbon source, the strain did not support growth; thus, indicating that in addition to conferring a dominant negative phenotype, expression of the human HA-MYBBP1A allele was unable to complement the lethal phenotype linked to the POL5 deletion (Supplemental Fig. S13A). Western blot analysis of the HA-tagged protein indicated that the lack of complementation was not due to deficient protein expression (Supplemental Fig. S13B). We also tested whether human HA-MYBBP1A was able to rescue the ts phenotype of the conditional pol5-1 and pol5-3 alleles at the nonpermissive temperature $\left(37^{\circ} \mathrm{C}\right)$, but, as above, no complementation could be observed. Additionally, a negative effect on growth associated with expression of HAMYBBP1A was again revealed (data not shown). Importantly, the expression of HA-MYBBP1A interferes with the correct biogenesis of 60S r-subunits as shown by polysome profile analysis (Supplemental Fig. S14). Consequently, despite the sequence homology and the fact that both proteins could have a role in 60S r-subunit biogenesis, our data are not conclusive enough to reveal that human MYBBP1A and yeast Pol5 exert the same molecular function.

\section{DISCUSSION}

In this work, we show that Pol5 is a ribosome biogenesis factor that can be grouped into the RRB/RiBi gene class as its expression is coregulated with that of the bulk of factors belonging to these regulons. As most RRB/RiBi genes, POL5 is a TATA-less gene (data not shown). Promoter 
sequence analysis revealed that the genes within the RRB regulon are enriched in the RRPE [consensus sequence $5^{\prime}$ TGAAAA(A/T)TTT(C/T) $3^{\prime}$ ] and PAC [consensus sequence 5' GCGATGAG(A/C)T 3'] motifs (Wade et al. 2006; Bosio et al. 2011). The consensus sequences of these elements are absent in the POL5 promoter, however, an 11-base RRPE-like element $5^{\prime}$ CGAAAAATTTT $3^{\prime}$ and a PAC-like element 5' GCGATGGCCA $3^{\prime}$ containing one and three mismatches (underlined bases) to the consensus sequences were found at positions -151 and -137 with respect to the first base of the start codon, respectively. Remarkably, both the positions and the relative order of these elements also coincide with that of a typical RRB gene promoter as they are found in the POL5 promoter in the first $150 \mathrm{bp}$ upstream of the start codon, with the PAC-like element being more proximal to the start codon and spaced by less than 50 bp relative to the RRPE-like element. Whether these sequence elements in the POL5 promoter could efficiently act as recognition sites for the transcription regulators that bind the canonical elements of bona fide RRB/RiBi gene promoters needs to be determined (for further details, see Bosio et al. 2017), although this would be expected given the common coregulation.

Our data establish that Pol5 is a component of early/medium nucle(ol)ar pre-60S r-particles containing 27S prerRNAs. Previous work has identified Pol5 as a component of the t-Utp/UtpA subcomplex of 90S preribosomal particles (Gallagher et al. 2004; Krogan et al. 2004). However, more recently, it has been reported that Pol5 is rather a t-UTP/UtpA accessory factor, which dissociates from the subcomplex before the incorporation of this latter into nascent 905 preribosomal particles (Gallagher 2019). The association of Pol5 with pre-60S r-particles was not previously unveiled despite the abundant information available on the composition of different affinity-purified pre-60S complexes (e.g., Fromont-Racine et al. 2003). This fact is likely due to the weak and/or transient association of Pol5 with preribosomal particles. Indeed, the enrichment of $27 \mathrm{~S}$ pre-rRNAs we obtained by the affinity purification of GFP-tagged Pol5 was clearly poorer than what we have previously observed for purifications of other GFPtagged ribosome biogenesis factors or r-proteins (e.g., Babiano and de la Cruz 2010; Espinar-Marchena et al. 2018).

In this paper, we also describe the functional analysis of Pol5 in ribosome biogenesis. In vivo depletion of Pol5 leads to a deficit in 60S r-subunits as revealed by polysome analyses, which showed the appearance of half-mers, and by quantification of total r-subunits. Detailed analysis of pre-rRNA processing by northern hybridization and primer extension suggested that this deficit is the result of impaired maturation of medium pre-60S r-particles containing $27 \mathrm{SB}$ pre-rRNAs; hence, both $27 \mathrm{SB}_{\mathrm{S}}$ and $27 \mathrm{SB}_{\mathrm{L}}$ species clearly accumulated upon Pol5 depletion. Some accumulation of the upstream $27 \mathrm{SA}_{3}$ pre-rRNA was also detected; however, no drastic depletion of the downstream $7 \mathrm{~S}$ and $25.5 \mathrm{~S}$ precursors could be observed, suggesting that the pre-60S intermediates undergoing ITS2 processing are also being stabilized during the time course of Pol5 depletion. Moreover, we also observed an accumulation of the $35 \mathrm{~S}$ pre-rRNA, the appearance of the aberrant $23 \mathrm{~S}$ species and the concomitant mild reduction of $27 \mathrm{SA}_{2}$ and $20 \mathrm{~S}$ pre-rRNAs. This is consistent with a delayed processing at the early $A_{0}, A_{1}$, and $A_{2}$ cleavage sites upon Pol5 depletion that, however, affects only minorly the overall synthesis of $18 \mathrm{~S}$ rRNA and $40 \mathrm{~S}$ r-subunit production. Delayed processing of $35 \mathrm{~S}$ pre-rRNA, which is common for practically all loss-of-function mutations in genes involved in 60S r-subunit biogenesis including 60S r-proteins, has previously been well discussed (e.g., Axt et al. 2014; Espinar-Marchena et al. 2016; Talkish et al. 2016) and arises as the consequence of a functional limitation of early trans-acting factors that are sequestered on aberrant pre-60S intermediates and/or the specific switch of pre-rRNA processing to the so-called $A_{3}$ pathway (KosBraun et al. 2017). Recently, Gallagher has reported comparable results after assessing the steady-state levels of pre-rRNAs from an equivalent GAL::POL5 strain shifted to glucose medium for $24 \mathrm{~h}$ (Gallagher 2019). It is unlikely that Pol5 plays a direct role in 27SB pre-rRNA processing. Instead, Pol5 may fulfill a more general function as a pre$60 \mathrm{~S}$ ribosomal assembly factor. It has been reported that Pol5 has DNA polymerase activity in vitro (Shimizu et al. 2002); however, the in vivo relevance of this activity is unclear as the pol5dn mutant, which expresses a Pol5 [D623N;D625N] protein displaying no in vitro DNA polymerase activity, exhibits similar growth and global translation capacity, as indicated by polysome profile analysis, as the wild-type strain (Supplemental Figs. S3, S7; Shimizu et al. 2002). The pre-rRNA processing defects revealed by the depletion of Pol5 are accompanied by a retention of uL23-eGFP containing pre-60S r-particles in the nucle(ol)us. This phenotype is also very common for mutations affecting different nucle(ol)ar steps of $60 \mathrm{~S}$ r-subunit maturation and appears as the result of a possible quality control mechanism that normally disables defective pre-60S r-particles to acquire nucleo-cytoplasmic export competence (e.g., see Thomson and Tollervey 2005; Babiano and de la Cruz 2010 and for a discussion Bassler and Hurt 2019).

The pre-rRNA processing and nuclear export defects shown by the Pol5-depleted strain closely resemble those described for loss-of-function mutations in or depletion of distinct $60 \mathrm{~S}$ r-subunit biogenesis factors and $60 \mathrm{~S} \mathrm{r-pro-}$ teins. About 16 trans-acting factors, the so-called "B-factors," are required for cleavage of 27SB pre-rRNAs at site $\mathrm{C}_{2}$ (Talkish et al. 2012; Woolford and Baserga 2013). Association of the B-factors with preribosomal particles takes place in two stages: most B-factors are recruited to early pre-60S r-particles containing the $27 \mathrm{SA}_{2}$ pre-rRNA, 
while others, such as Nsa2 and Nog2, seem to associate later, just prior to cleavage at site $\mathrm{C}_{2}$ (see Woolford and Baserga 2013 and references therein). Recent cryo-EM analyses of early pre-60S r-particles indicate that by the time most B-factors appear to be stably bound, the six 25S/5.8S rRNAs domains have been folded but not fully compacted (Kater et al. 2017; Sanghai et al. 2018; Bassler and Hurt 2019; Klinge and Woolford 2019). These results are consistent with those obtained by studying the composition of purified pre-60S r-particles containing progressively 3 '-elongated fragments of $27 \mathrm{~S}$ pre-rRNA (Chen et al. 2017; Chaker-Margot and Klinge 2019) and those of high-throughput RNA structure probing analyses on purified nucleolar pre-60S r-particles (Burlacu et al. 2017). Regarding r-proteins, several 605 r-subunit proteins, including uL6, uL22, eL19, uL14, uL23, uL24, eL27, eL34, uL29, and eL37 (formerly L9, L17, L19, L23, L25, $L 26, L 27, L 34, L 35$, and L37, respectively), have been reported to be more or less important for efficient conversion of $27 \mathrm{SB}$ into $7 \mathrm{~S}$ and $25.5 \mathrm{~S}$ pre-rRNAs (see de la Cruz et al. 2015 and references therein). All of these r-proteins assemble into pre-60S r-particles before cleavage at site $\mathrm{C}_{2}$; strikingly, assembly of at least uL6, uL14, uL22, $\mathrm{uL23}, \mathrm{uL29}$, eL27, eL37 and, to a lesser extent, uL24 is necessary to properly recruit the B-factors Nsa2 and Nog2 to pre-60S r-particles, and other factors such as Noc3 and Nop53, with the latter, then acting as the recruitment factor for Mtr4 and the exosome (Babiano et al. 2012; Gamalinda et al. 2013, 2014; Ohmayer et al. 2013; Thoms et al. 2015).

To further analyze the function of Pol5 during 605 r-subunit biogenesis, we performed a multicopy suppressor screen with the pol5-1 ts mutant and isolated the genes encoding the 60S r-proteins $\mathrm{uL} 23$ and eL27A, which were unable to suppress the lethality of a pol5 $\Delta$ allele. Although high-dosage of each of the two genes, alone or together, efficiently suppressed the growth defect of the pol5-1 mutant at $37^{\circ} \mathrm{C}$, only when both are simultaneously overexpressed the $60 \mathrm{~S}$ r-subunit shortage is minorly alleviated. This result suggests an improvement of the functional competence of the produced ribosomes in the suppressed strains rather than a restoration of the $605 \mathrm{r}$ subunit deficiency as an explanation for the suppression at the molecular level. Few other examples, where multicopy suppressors rescue the growth defect of ribosome biogenesis factor mutants without concomitantly increasing the levels of the corresponding r-subunits, have been reported. These include the suppression of certain ebp2 mutants by eL36A/B (Wan et al. 2013), of a distinct rrp5 allele by snR10 (Torchet and Hermann-Le Denmat 2002), of a tsr2 mutant by uS11 (Peña et al. 2016) or of the rrp2-1 mutant by Pop3 (Dichtl and Tollervey 1997). Very recently, it has been found by UV cross-linking and analysis of cDNAs (CRAC) that Pol5 directly contacts the 25S rRNA at several sites within domain III (J. Pérez-Fernández, pers. comm.), where, strikingly, both uL23 and eL27 also bind to intermediate pre-60S r-particles and mature 60S r-subunits (Ben-Shem et al. 2011; Wu et al. 2016; Kater et al. 2017; Sanghai et al. 2018). This suggests that Pol5 could be involved in achieving the proper structural conformation of $25 \mathrm{~S}$ rRNA domain III by promoting the stable incorporation of distinct r-proteins, such as uL23 and eL27. The fact that the co-overexpression of uL23 and eL27 increases the suppression efficiency of the pol5-1 mutant is consistent with this scenario. Also consistent with this hypothesis, affinity purified pre-60S r-particles depleted of Pol5 are severely deprived of $u L 23$ and eL27 (J. PérezFernández, pers. comm.).

Finally, we explored whether human MYBBP1A and yeast Pol5 are functional orthologs. However, expression of a human HA-tagged MYBBP1A construct did not complement the lethal phenotype of a pol5 $\Delta$ null strain. Despite this negative result, some relevant coincidences make us suspect that they could perform similar functions during ribosome biogenesis: (i) Both MYBBP1A and Pol5 are nucleolar proteins (Tavner et al. 1998) and (ii) importantly, knockdown of MYBBP1A in different cultured human cell types leads to impaired pre-rRNA processing, more specifically, accumulation of $47 \mathrm{~S}$ and $32 \mathrm{~S}$ prerRNAs, which are the human equivalents to $35 \mathrm{~S}$ and 27SB pre-rRNAs (Tafforeau et al. 2013). Strikingly, the expression of MYBBP1A exerted a strong negative effect on yeast growth and led to a deficit in 605 r-subunits. As a simple explanation for this result, MYBBP1A could be sequestering an essential factor required for $60 \mathrm{~S}$ r-subunit biogenesis; alternatively, it could be making an unproductive binding on pre-60S r-particles. Further experiments are required to reveal whether this factor is specifically related to 605 r-subunit biogenesis in mammalian cells as Pol5 is in yeast. It has been shown that MYBBP1A connects ribosome biogenesis and growth; thus, upon inhibition of rRNA synthesis, MYBBP1A translocates to the nucleoplasm and increases the acetylation levels of p53 (Kuroda et al. 2011). A challenge for future studies will be to elucidate the molecular mechanism underlying these connections, which are crucial to understand cancer development.

\section{MATERIALS AND METHODS}

\section{Strains and microbiological methods}

Yeast strains used in this study are listed in Supplemental Table S1. Some are derived from the W303 strain (Thomas and Rothstein 1989): YJP38 is a conditional strain that genomically expresses an HA-tagged version of Pol5 under the control of the GAL1 promoter. This strain (referred to in the text as GAL::HA$P O L 5)$ was generated by one-step insertion of a kanMX6PGAL1-3xHA cassette upstream of the ATG of the POL5 gene (Longtine et al. 1998). The YMP1 strain expresses a fully functional 
carboxy-terminally GFP-tagged Pol5 under the control of its cognate promoter; the GFP(S65T) tag allele was fused by in frame one-step integration of a PCR cassette in the corresponding wildtype genomic locus of the W303-1A strain (Longtine et al. 1998). Y10143 and Y10144 strains, kindly provided by C. Boone, are genomic pol5-1 and pol5-3 mutant strains, respectively, in the BY4742 yeast background (Li et al. 2011); the ts pol5-1 allele encodes the variant Pol5[V404M;K491E;Q671P] protein, while the ts pol5-3 allele encodes the variant Pol5[W292R] protein (Shimizu et al. 2002). DGY115 is a pol5 null haploid segregant of yeast Y20296 (BY4743 yeast background; Euroscarf), which expresses Pol5 from its cognate promoter from plasmid YCplac33.

Yeast genetic techniques and growth media have been previously described (Burke et al. 2000). Strains were grown at selected temperatures either in rich YP medium (1\% yeast extract, $2 \%$ peptone) supplemented with $0.2 \%$ adenine and containing either $2 \%$ glucose (YPD) or $2 \%$ galactose (YPGal) as carbon source. We also used synthetic minimal medium $(0.15 \%$ yeast nitrogen base, $0.5 \%$ ammonium sulfate) supplemented with the appropriate amino acids and bases as nutritional requirements, and containing either $2 \%$ glucose (SD) or $2 \%$ galactose (SGal) as carbon source. For in vivo depletion of Pol5, the GAL::HA-POL5 strain was grown in liquid YPGal medium at $30^{\circ} \mathrm{C}$ until mid-exponential phase $\left(O D_{600}\right.$ of 0.8 ), and then harvested, washed and transferred to liquid YPD broth. Cell growth was monitored over a period of $12 \mathrm{~h}$, during which the cultures were regularly diluted into fresh YPD medium. Yeast transformation was done by the lithium acetate method (Gietz et al. 1992). After sporulation, tetrads were dissected using a Singer MSM micromanipulator. Standard molecular biology techniques were as previously described (Sambrook et al. 1989). Escherichia coli $\mathrm{DH} 5 \alpha$ was used for cloning and propagation of plasmids (Sambrook et al. 1989).

\section{Multicopy suppression analysis}

To isolate multicopy suppressor of pol5 mutants, the Y10143 strain (pol5-1 mutant) was transformed with a YEplac181-based yeast genomic library (de la Cruz et al. 1997). Transformants were spread on SD-Leu plates and incubated for 3-5 d at the nonpermissive temperature of $37^{\circ} \mathrm{C}$. Plasmid DNA was isolated from the thermo-tolerant candidates, rescued in E. coli, and back-transformed into Y10143. Four clones out of approximately 35,000 transformants were found to reproducibly suppress the ts phenotype of the pol5-1 mutant. The inserts of the rescued plasmids were sequenced revealing that one contained the POL5 gene, another one contained DNA corresponding to the RPL25-TRM13 region of chromosome $\mathrm{XV}$ and the last two ones contained DNA fragments from chromosome VIII where only the RPL27A and DIA4 genes were shared. Further cloning into YEplac181 or YEplac195 of PCR-amplified fragments containing either the RPL27A or RPL25 gene defined these genes as the multicopy suppressors of the pol5-1 mutant.

\section{Plasmids}

All plasmids used in this study are listed in Supplemental Table S2. To construct YCplac33-, and YCplac111-POL5, a PCR was performed using yeast genomic DNA as a template and oligonucleotides placed $\pm 1 \mathrm{kbp}$ upstream and downstream from the start- stop codon of the POL5 ORF, respectively; after the appropriate restriction digestion, the $\mathrm{PCR}$ product was cloned into the particular vectors. The pol5dn allele, which codes for a catalytically inactive Pol5[D623N;D625N] protein (Shimizu et al. 2002), was generated with the $\mathrm{Q} 5$ site-directed mutagenesis kit (NEB) with YCplac111-POL5 as a template. The full-length cDNA of human MYBBP1A was PCR-amplified from pACT-Flag-MYBBP1A, a gift from A. Carnero (Hochstatter et al. 2012), and cloned into the pAS24 plasmid under the transcriptional control of the GAL1 promoter. Further details on the construction of the plasmids are available upon request. The plasmids pRS314-DsRed-NOP1, pRS316-RPS3-eGFP-NOP1-mRFP, and pRS316-RPL25-eGFPNOP1-mRFP, a gift from J. Bassler and E. Hurt, have been previously reported (Ulbrich et al. 2009).

\section{Sucrose gradient centrifugation}

Polyribosome and r-subunit preparations and analyses were done as described previously (Kressler et al. 1998). Gradient analysis was performed with an ISCO UA-6 system, with continuous monitoring at $A_{254}$. In all cases, extracts were performed from cell cultures harvested at an $\mathrm{OD}_{600}$ of approximately 0.8 and about 10 $A_{260}$ units of each extract were loaded in gradients. To quantify the $605 / 40 S$ ratios, each r-subunit profile was enlarged to occupy the maximum space in an A4 size paper and printed three times; then, the area under each r-subunit peak was cut and weighed. The mean of the three independent measurements was calculated. Three independent biological replicates were performed for each experiment and the means recalculated in each case.

\section{Protein extractions and western blotting analyses}

Total yeast protein extracts were prepared and analyzed by western blotting according to standard procedures (Sambrook et al. 1989; Ausubel et al. 1994). High-affinity mouse monoclonal anti-HA (Roche), anti-GFP (Roche), and anti-Pgk1 (Invitrogen) were used as primary antibodies. Secondary goat anti-mouse horseradish peroxidase-conjugated antibodies (Bio-Rad) were used. Proteins were detected using a chemiluminescence detection kit (Super-signal West Pico, Pierce) and a ChemiDoc MP system (Bio-Rad).

\section{RNA extractions and steady-state analysis of pre- rRNAs and mature rRNAs}

Total RNA was extracted by the hot acidic phenol-chloroform procedure (Ausubel et al. 1994). Normally, RNA was extracted from samples corresponding to $10 \mathrm{OD}_{600}$ units of cells grown to midlog phase. Northern hybridization and primer extension analyses were carried out as previously described (Kressler et al. 1998; Venema et al. 1998). Equal amounts of total RNA were loaded on gels or used for primer extension reactions. Specific oligonucleotides (see Supplemental Table S3 for their sequences) were 5 '-end labeled with $[\gamma-32 P]$ ATP and used as probes. Hybridization signals were detected using a Typhoon FLA9400 imaging system (GE Healthcare). 


\section{Affinity purification of Pol5-GFP}

Complexes containing GFP-tagged Pol5 protein were precipitated following the one-step GFP-Trap A procedure (Chromotek) with GFP-Trap A beads, as exactly described in Babiano and de la Cruz (2010). The proteins from the purified complexes were extracted by boiling the beads with Laemmli buffer and analyzed by western blotting (Espinar-Marchena et al. 2016). Pre- and mature rRNAs were recovered from the beads by phenol-chloroform extraction and assayed by northern hybridization as indicated above.

\section{Fluorescence microscopy}

To address the subcellular localization of Pol5, strain YMP1 was transformed with pRS314-DsRed-NOP1 and transformants grown in selective SD medium. To test preribosomal particle nuclear export, the GAL::HA-POL5 strain was transformed with plasmids expressing either GFP-tagged uL23 or uS3 and Nop1-mRFP (see above); transformants were grown in selective SGal medium and shifted to selective SD medium to deplete Pol5. Cells were washed, resuspended in PBS buffer $(140 \mathrm{mM} \mathrm{NaCl}, 8 \mathrm{mM}$ $\mathrm{Na}_{2} \mathrm{HPO}_{4}, 1.5 \mathrm{mM} \mathrm{KH}_{2} \mathrm{PO}_{4}, 2.75 \mathrm{mM} \mathrm{KCl}, \mathrm{pH}$ 7.3), and examined with a Leica DMR fluorescence microscope equipped with a DC350F digital camera and its software. Adobe Photoshop CC (Adobe Systems, Inc.) was used to process the images.

\section{Bioinformatic analysis}

The promoter region of POL5 was searched for the presence of the RRB-associated RRPE and PAC motifs by a bioinformatic analysis. A degenerated RRPE sequence was found searching the promoter region of POL5 for the consensus sequence $5^{\prime}$ TGAAAA (A/T)TTT(C/T) 3' (Bosio et al. 2011), using the function matchPattern of the Biostrings package of $\mathrm{R}$, with the following settings (max.mismatch $=1$, fixed $=$ FALSE), starting at position -151 from the first base of the start codon. The PAC sequence was searched looking for the consensus sequence $5^{\prime}$ GCGATGAG(A/C)T 3' (Bosio et al. 2011), using also the function matchPattern of the Biostrings package of R software (www.rproject.org). To find any relevant match, the settings had to include at least three mismatches (max.mismatch $=3$, fixed $=$ FALSE); thus, the sequence 5' GCGATGGCCA 3' was found starting at position -137 and the sequence $5^{\prime}$ CCCATCAGCT $3^{\prime}$ was found starting at position -403 relative to the start codon.

A list of 65 RRB genes has been published in Wade et al. (2001). A list of $236 \mathrm{RiBi}$ genes is described in Jorgensen et al. (2004). The four data sets employed in this study were described in Wade et al. (2006), corresponding to expression profiles of cells subjected to release of an $\alpha$-factor arrest (Spellman et al. 1998), progressing through the sporulation pathway (Chu et al. 1998), or subjected to heat shock (Gasch et al. 2000) or osmotic stress (Gasch et al. 2000). All data of these four expression data sets were consolidated in a single data table for the combined analysis. The PCA was performed using the prcomp function of the $R$ base package with default settings. The values of cDNA expression were extracted as normalized, background corrected Cy3: Cy5 ratios from the different original publications and used as input for the analysis. Genes with missing values were excluded from the analysis. The PCA with the data contained in Jorgensen et al. (2004) was performed with the whole expression data set except for one of the time points that was excluded from the analysis due to missing the value for POL5.

\section{SUPPLEMENTAL MATERIAL}

Supplemental material is available for this article.

\section{ACKNOWLEDGMENTS}

We thank those colleagues mentioned in the text for supplying material used in this work. We are deeply indebted to J. PérezFernández for communicating results prior to publication. We also thank D. Kressler for critical reading of the manuscript. This work was supported by the Spanish Ministry of Economy and Competitiveness (MINECO) and ERDF to J.d.I.C. (BFU201675352-P AEI/FEDER, EU) and to M.D. (BFU2014-52729-P, BFU2017-88192-P). D.G.-A. is a recipient of a contract of the Youth Employment Initiative from the University of Seville/Junta de Andalucía/European Social Fund.

Received May 24, 2019; accepted August 8, 2019.

\section{REFERENCES}

Ausubel FM, Brent R, Kingston RE, Moore DD, Seidman JG, Smith JA, Struhl K. 1994. Saccharomyces cerevisiae. In Current protocols in molecular biology, pp. 13.10.11-13.14.17. Wiley, NY.

Axt K, French SL, Beyer AL, Tollervey D. 2014. Kinetic analysis demonstrates a requirement for the Rat1 exonuclease in cotranscriptional pre-rRNA cleavage. PLoS One 9: e85703. doi:10.1371/journal pone.0085703

Babiano R, de la Cruz J. 2010. Ribosomal protein L35 is required for 27SB pre-rRNA processing in Saccharomyces cerevisiae. Nucleic Acids Res 38: 5177-5192. doi:10.1093/nar/gkq260

Babiano R, Gamalinda M, Woolford JL Jr., de la Cruz J. 2012. Saccharomyces cerevisiae ribosomal protein L26 is not essential for ribosome assembly and function. Mol Cell Biol 32: 32283241. doi:10.1128/MCB.00539-12

Barandun J, Hunziker M, Klinge S. 2018. Assembly and structure of the SSU processome-a nucleolar precursor of the small ribosomal subunit. Curr Opin Struct Biol 49: 85-93. doi:10.1016/j.sbi.2018 .01 .008

Bassler J, Hurt E. 2019. Eukaryotic ribosome assembly. Annu Rev Biochem 88: 281-306. doi:10.1146/annurev-biochem-013118110817

Bassler J, Grandi P, Gadal O, Lessmann T, Petfalski E, Tollervey D, Lechner J, Hurt E. 2001. Identification of a 605 preribosomal particle that is closely linked to nuclear export. Mol Cell 8: 517-529. doi:10.1016/S1097-2765(01)00342-2

Ben-Shem A, Garreau de Loubresse N, Melnikov S, Jenner L, Yusupova G, Yusupov M. 2011. The structure of the eukaryotic ribosome at $3.0 \AA$ resolution. Science 334: 1524-1529. doi:10 $.1126 /$ science. 1212642

Bosio MC, Negri R, Dieci G. 2011. Promoter architectures in the yeast ribosomal expression program. Transcription 2: 71-77. doi:10 $.4161 /$ trns.2.2.14486

Bosio MC, Fermi B, Dieci G. 2017. Transcriptional control of yeast ribosome biogenesis: a multifaceted role for general regulatory factors. Transcription 8: 254-260. doi:10.1080/21541264.2017 .1317378 
Broach JR. 2012. Nutritional control of growth and development in yeast. Genetics 192: 73-105. doi:10.1534/genetics.111.135731

Burke D, Dawson D, Stearns T. 2000. Methods in yeast genetics: a Cold Spring Harbor Laboratory course manual. Cold Spring Harbor Laboratory Press, Cold Spring Harbor, NY.

Burlacu E, Lackmann F, Aguilar LC, Belikov S, Nues RV, Trahan C, Hector RD, Dominelli-Whiteley N, Cockroft SL, Wieslander L, et al. 2017. High-throughput RNA structure probing reveals critical folding events during early $60 \mathrm{~S}$ ribosome assembly in yeast. Nat Commun 8: 714. doi:10.1038/s41467-017-00761-8

Causton HC, Ren B, Koh SS, Harbison CT, Kanin E, Jennings EG, Lee TI, True HL, Lander ES, Young RA. 2001. Remodeling of yeast genome expression in response to environmental changes. Mol Biol Cell 12: 323-337. doi:10.1091/mbc.12.2.323

Chaker-Margot M, Klinge S. 2019. Assembly and early maturation of large subunit precursors. RNA 25: 465-471. doi:10.1261/rna .069799 .118

Chaker-Margot M, Hunziker M, Barandun J, Dill BD, Klinge S. 2015. Stage-specific assembly events of the 6-MDa small-subunit processome initiate eukaryotic ribosome biogenesis. Nat Struct Mol Biol 22: 920-923. doi:10.1038/nsmb.3111

Chen W, Xie Z, Yang F, Ye K. 2017. Stepwise assembly of the earliest precursors of large ribosomal subunits in yeast. Nucleic Acids Res 45: 6837-6847. doi:10.1093/nar/gkx254

Chu S, DeRisi J, Eisen M, Mulholland J, Botstein D, Brown PO, Herskowitz I. 1998. The transcriptional program of sporulation in budding yeast. Science 282: 699-705. doi:10.1126/science.282 .5389 .699

de la Cruz J, lost I, Kressler D, Linder P. 1997. The p20 and Ded1 proteins have antagonistic roles in elF4E-dependent translation in Saccharomyces cerevisiae. Proc Natl Acad Sci 94: 5201-5206. doi:10.1073/pnas.94.10.5201

de la Cruz J, Karbstein K, Woolford JL Jr. 2015. Functions of ribosomal proteins in assembly of eukaryotic ribosomes in vivo. Annu Rev Biochem 84: 93-129. doi:10.1146/annurev-biochem-060614033917

Dichtl B, Tollervey D. 1997. Pop3p is essential for the activity of the RNase MRP and RNase $P$ ribonucleoproteins in vivo. EMBO J 16: 417-429. doi:10.1093/emboj/16.2.417

Espinar-Marchena FJ, Fernández-Fernández J, Rodríguez-Galán $O$, Fernández-Pevida A, Babiano R, de la Cruz J. 2016. Role of the yeast ribosomal protein L16 in ribosome biogenesis. FEBS $J$ 283: 2968-2985. doi:10.1111/febs.13797

Espinar-Marchena F, Rodríguez-Galán O, Fernández-Fernández J, Linnemann J, de la Cruz J. 2018. Ribosomal protein L14 contributes to the early assembly of 605 ribosomal subunits in Saccharomyces cerevisiae. Nucleic Acids Res 46: 4715-4732. doi:10.1093/nar/gky123

Fatica A, Oeffinger M, Tollervey D, Bozzoni I. 2003. Cic1 p/Nsa3p is required for synthesis and nuclear export of $60 \mathrm{~S}$ ribosomal subunits. RNA 9: 1431-1436. doi:10.1261/rna.5130503

Felipe-Abrio B, Verdugo-Sivianes EM, Sáez C, Carnero A. 2019. Loss of MYBBP1A induces cancer stem cell activity in renal cancer. Cancers (Basel) 11: 235. doi:10.3390/cancers11020235

Fernández-Pevida A, Kressler D, de la Cruz J. 2015. Processing of preribosomal RNA in Saccharomyces cerevisiae. Wiley Interdiscip Rev RNA 6: 191-209. doi:10.1002/wrna.1267

Ferreira-Cerca S, Pöll G, Gleizes PE, Tschochner H, Milkereit P. 2005. Roles of eukaryotic ribosomal proteins in maturation and transport of pre-18S rRNA and ribosome function. Mol Cell 20: 263-275. doi:10.1016/j.molcel.2005.09.005

Ferreira-Cerca S, Kiburu I, Thomson E, LaRonde N, Hurt E. 2014. Dominant Rio1 kinase/ATPase catalytic mutant induces trapping of late pre-40S biogenesis factors in 80S-like ribosomes. Nucleic Acids Res 42: 8635-8647. doi:10.1093/nar/gku542
Fromont-Racine M, Senger B, Saveanu C, Fasiolo F. 2003. Ribosome assembly in eukaryotes. Gene 313: 17-42. doi:10.1016/S03781119(03)00629-2

Gallagher JEG. 2019. Proteins and RNA sequences required for the transition of the $\mathrm{t}-\mathrm{Utp}$ complex into the SSU processome. FEMS Yeast Res 19: foy120. doi:10.1093/femsyr/foy120

Gallagher JE, Dunbar DA, Granneman S, Mitchell BM, Osheim Y, Beyer AL, Baserga SJ. 2004. RNA polymerase I transcription and pre-rRNA processing are linked by specific SSU processome components. Genes Dev 18: 2506-2517. doi:10.1101/gad.1226604

Gamalinda M, Jakovljevic J, Babiano R, Talkish J, de la Cruz J, Woolford JL Jr. 2013. Yeast polypeptide exit tunnel ribosomal proteins L17, L35 and L37 are necessary to recruit late-assembling factors required for $27 \mathrm{SB}$ pre-rRNA processing. Nucleic Acids Res 41: 1965-1983. doi:10.1093/nar/gks1272

Gamalinda M, Ohmayer U, Jakovljevic J, Kumcuoglu B, Woolford J, Mbom B, Lin L, Woolford JL Jr. 2014. A hierarchical model for assembly of eukaryotic 60S ribosomal subunit domains. Genes Dev 28: 198-210. doi:10.1101/gad.228825.113

Gasch AP, Spellman PT, Kao CM, Carmel-Harel O, Eisen MB, Storz G, Botstein D, Brown PO. 2000. Genomic expression programs in the response of yeast cells to environmental changes. Mol Biol Cell 11: 4241-4257. doi:10.1091/mbc.11.12.4241

Gavin AC, Aloy P, Grandi P, Krause R, Boesche M, Marzioch M, Rau C, Jensen LJ, Bastuck S, Dümpelfeld B, et al. 2006. Proteome survey reveals modularity of the yeast cell machinery. Nature 440: 631636. doi: $10.1038 /$ nature 04532

Gietz D, St. Jean A, Woods RA, Schiestl RH. 1992. Improved method for high efficiency transformation of intact yeast cells. Nucleic Acids Res 20: 1425. doi:10.1093/nar/20.6.1425

Grandi P, Rybin V, Bassler J, Petfalski E, Strauss D, Marzioch M, Schäfer T, Kuster B, Tschochner H, Tollervey D, et al. 2002. 90S pre-ribosomes include the $35 \mathrm{~S}$ pre-rRNA, the U3 snoRNP, and $40 \mathrm{~S}$ subunit processing factors but predominantly lack 60 S synthesis factors. Mol Cell 10: 105-115. doi:10.1016/S1097-2765(02) 00579-8

Harnpicharnchai P, Jakovljevic J, Horsey E, Miles T, Roman J, Rout M, Meagher D, Imai B, Guo Y, Brame CJ, et al. 2001. Composition and functional characterization of yeast $66 \mathrm{~S}$ ribosome assembly intermediates. Mol Cell 8: 505-515. doi:10.1016/S1097-2765(01) 00344-6

Henras AK, Soudet J, Gérus M, Lebaron S, Caizergues-Ferrer M, Mougin A, Henry Y. 2008. The post-transcriptional steps of eukaryotic ribosome biogenesis. Cell Mol Life Sci 65: 2334-2359. doi:10 .1007/s00018-008-8027-0

Hochstatter J, Hölzel M, Rohrmoser M, Schermelleh L, Leonhardt H, Keough R, Gonda TJ, Imhof A, Eick D, Längst G, et al. 2012. Myb-binding protein 1a (Mybbp1a) regulates levels and processing of pre-ribosomal RNA. J Biol Chem 287: 24365-24377. doi:10.1074/jbc.M111.303719

Jenner L, Melnikov S, de Loubresse NG, Ben-Shem A, Iskakova M, Urzhumtsev A, Meskauskas A, Dinman J, Yusupova G, Yusupov M. 2012. Crystal structure of the 80S yeast ribosome. Curr Opin Struct Biol 22: 759-767. doi:10.1016/j.sbi.2012.07.013

Jorgensen P, Nishikawa JL, Breitkreutz BJ, Tyers M. 2002. Systematic identification of pathways that couple cell growth and division in yeast. Science 297: 395-400. doi:10.1126/science.1070850

Jorgensen P, Rupes I, Sharom JR, Schneper L, Broach JR, Tyers M. 2004. A dynamic transcriptional network communicates growth potential to ribosome synthesis and critical cell size. Genes Dev 18: 2491-2505. doi:10.1101/gad.1228804

Kater L, Thoms M, Barrio-García C, Cheng J, Ismail S, Ahmed YL, Bange G, Kressler D, Berninghausen O, Sinning I, et al. 2017. Visualizing the assembly pathway of nucleolar pre-60S ribosomes. Cell 171: 1599-1610.e14. doi:10.1016/j.cell.2017.11.039 
Klinge S, Woolford JL Jr. 2019. Ribosome assembly coming into focus. Nat Rev Mol Cell Biol 20: 116-131. doi:10.1038/s41580018-0078-y

Klinge S, Voigts-Hoffmann F, Leibundgut M, Ban N. 2012. Atomic structures of the eukaryotic ribosome. Trends Biochem Sci 37: 189-198. doi:10.1016/j.tibs.2012.02.007

Konikkat S, Woolford JL Jr. 2017. Principles of 60 S ribosomal subunit assembly emerging from recent studies in yeast. Biochem $\mathrm{J}$ 474: 195-214. doi:10.1042/BCJ20160516

Kos-Braun IC, Jung I, Koš M. 2017. Tor1 and CK2 kinases control a switch between alternative ribosome biogenesis pathways in a growth-dependent manner. PLoS Biol 15: e2000245. doi:10 .1371/journal.pbio. 2000245

Kressler D, de la Cruz J, Rojo M, Linder P. 1998. Dbp6p is an essential putative ATP-dependent RNA helicase required for 60S-ribosomal-subunit assembly in Saccharomyces cerevisiae. Mol Cell Biol 18: 1855-1865. doi:10.1128/MCB.18.4.1855

Kressler D, Linder P, de la Cruz J. 1999. Protein trans-acting factors involved in ribosome biogenesis in Saccharomyces cerevisiae. Mol Cell Biol 19: 7897-7912. doi:10.1128/MCB.19.12.7897

Kressler D, Roser D, Pertschy B, Hurt E. 2008. The AAA ATPase Rix7 powers progression of ribosome biogenesis by stripping Nsa1 from pre-60S particles. J Cell Biol 181: 935-944. doi:10.1083/ jcb.200801181

Kressler D, Hurt E, Bassler J. 2010. Driving ribosome assembly. Biochim Biophys Acta 1803: 673-683. doi:10.1016/j.bbamcr .2009.10.009

Kressler D, Hurt E, Bassler J. 2017. A puzzle of life: crafting ribosomal subunits. Trends Biochem Sci 42: 640-654. doi:10.1016/j.tibs .2017.05.005

Krogan NJ, Peng WT, Cagney G, Robinson MD, Haw R, Zhong G, GuoX, Zhang X, Canadien V, Richards DP, et al. 2004. High-definition macromolecular composition of yeast RNA-processing complexes. Mol Cell 13: 225-239. doi:10.1016/S1097-2765(04)00003-6

Kuroda T, Murayama A, Katagiri N, Ohta YM, Fujita E, Masumoto H, Ema M, Takahashi S, Kimura K, Yanagisawa J. 2011. RNA content in the nucleolus alters p53 acetylation via MYBBP1A. EMBO J 30: 1054-1066. doi:10.1038/emboj.2011.23

Li Z, Lee I, Moradi E, Hung NJ, Johnson AW, Marcotte EM. 2009. Rational extension of the ribosome biogenesis pathway using network-guided genetics. PLoS Biol 7: e1000213. doi:10.1371/jour nal.pbio. 1000213

Li Z, Vizeacoumar FJ, Bahr S, Li J, Warringer J, Vizeacoumar FS, Min R, Vandersluis B, Bellay J, Devit M, et al. 2011. Systematic exploration of essential yeast gene function with temperature-sensitive mutants. Nat Biotechnol 29: 361-367. doi:10.1038/nbt.1832

Longtine MS, McKenzie A III, Demarini DJ, Shah NG, Wach A, Brachat A, Philippsen P, Pringle JR. 1998. Additional modules for versatile and economical PCR-based gene deletion and modification in Saccharomyces cerevisiae. Yeast 14: 953-961. doi:10 $.1002 /(\mathrm{SICl}) 1097-0061(199807) 14: 10<953:: A I D-Y E A 293>3.0 . C O$ ;2-U

Melnikov S, Ben-Shem A, Garreau de Loubresse N, Jenner L, Yusupova G, Yusupov M. 2012. One core, two shells: bacterial and eukaryotic ribosomes. Nat Struct Mol Biol 19: 560-567. doi:10.1038/nsmb.2313

Milkereit P, Strauss D, Bassler J, Gadal O, Kühn H, Schütz S, Gas N, Lechner J, Hurt E, Tschochner H. 2003. A Noc-complex specifically involved in the formation and nuclear export of ribosomal $40 \mathrm{~S}$ subunits. J Biol Chem 278: 4072-4081. doi:10.1074/jbc.M208898200

Mori S, Bernardi R, Laurent A, Resnati M, Crippa A, Gabrieli A, Keough R, Gonda TJ, Blasi F. 2012. Myb-binding protein 1A (MYBBP1A) is essential for early embryonic development, controls cell cycle and mitosis, and acts as a tumor suppressor. PLoS One 7: e39723. doi:10.1371/journal.pone.0039723
Nerurkar P, Altvater M, Gerhardy S, Schütz S, Fischer U, Weirich C, Panse VG. 2015. Eukaryotic ribosome assembly and nuclear export. Int Rev Cell Mol Biol 319: 107-140. doi:10.1016/bs.ircmb .2015 .07 .002

Nissan TA, Bassler J, Petfalski E, Tollervey D, Hurt E. 2002. 60 S pre-ribosome formation viewed from assembly in the nucleolus until export to the cytoplasm. EMBO J 21: 5539-5547. doi:10.1093/ emboj/cdf547

Ohmayer U, Gamalinda M, Sauert M, Ossowski J, Pöll G, Linnemann J, Hierlmeier T, Perez-Fernández J, Kumcuoglu B, Leger-Silvestre I, et al. 2013. Studies on the assembly characteristics of large subunit ribosomal proteins in S. cerevisae. PLoS One 8: e68412. doi:10 .1371 /journal.pone.0068412

Peña C, Schütz S, Fischer U, Chang Y, Panse VG. 2016. Prefabrication of a ribosomal protein subcomplex essential for eukaryotic ribosome formation. Elife 5: e21755. doi:10.7554/eLife.21755

Peña C, Hurt E, Panse VG. 2017. Eukaryotic ribosome assembly, transport and quality control. Nat Struct Mol Biol 24: 689-699. doi:10 .1038/nsmb.3454

Peng WT, Robinson MD, Mnaimneh S, Krogan NJ, Cagney G, Morris Q, Davierwala AP, Grigull J, Yang X, Zhang W, et al. 2003. A panoramic view of yeast noncoding RNA processing. Cell 113: 919-933. doi:10.1016/S0092-8674(03)00466-5

Pérez-Fernández J, Román A, de las Rivas J, Bustelo XR, Dosil M. 2007. The $90 \mathrm{~S}$ preribosome is a multimodular structure that is assembled through a hierarchical mechanism. Mol Cell Biol 27: 5414-5429. doi:10.1128/MCB.00380-07

Pérez-Fernández J, Martín-Marcos P, Dosil M. 2011. Elucidation of the assembly events required for the recruitment of Utp20, Imp4 and Bms1 onto nascent pre-ribosomes. Nucleic Acids Res 39: 81058121. doi:10.1093/nar/gkr508

Pillet B, Mitterer V, Kressler D, Pertschy B. 2017. Hold on to your friends: dedicated chaperones of ribosomal proteins: dedicated chaperones mediate the safe transfer of ribosomal proteins to their site of pre-ribosome incorporation. Bioessays 39: 1-12. doi:10 .1002/bies.201600153

Pöll G, Braun T, Jakovljevic J, Neueder A, Jakob S, Woolford JL Jr., Tschochner H, Milkereit P. 2009. rRNA maturation in yeast cells depleted of large ribosomal subunit proteins. PLoS One 4: e8249. doi:10.1371/journal.pone.0008249

Rodríguez-Galán O, García-Gómez JJ, Kressler D, de la Cruz J. 2015. Immature large ribosomal subunits containing the 7S pre-rRNA can engage in translation in Saccharomyces cerevisiae. RNA Biol 12: 838-846. doi:10.1080/15476286.2015.1058477

Sambrook J, Fritsch EF, Maniatis T. 1989. Molecular cloning: a laboratory manual. Cold Spring Harbor Laboratory Press, Cold Spring Harbor, NY.

Sanghai ZA, Miller L, Molloy KR, Barandun J, Hunziker M, ChakerMargot M, Wang J, Chait BT, Klinge S. 2018. Modular assembly of the nucleolar pre-60S ribosomal subunit. Nature 556: 126129. doi:10.1038/nature26156

Sarkar A, Thoms M, Barrio-García C, Thomson E, Flemming D, Beckmann R, Hurt E. 2017. Preribosomes escaping from the nucleus are caught during translation by cytoplasmic quality control. Nat Struct Mol Biol 24: 1107-1115. doi:10.1038/nsmb.3495

Schäfer T, Strauss D, Petfalski E, Tollervey D, Hurt E. 2003. The path from nucleolar $90 \mathrm{~S}$ to cytoplasmic $40 \mathrm{~S}$ pre-ribosomes. EMBO J 22: 1370-1380. doi:10.1093/emboj/cdg121

Shimizu K, Kawasaki Y, Hiraga S, Tawaramoto M, Nakashima N, Sugino A. 2002. The fifth essential DNA polymerase $\phi$ in Saccharomyces cerevisiae is localized to the nucleolus and plays an important role in synthesis of rRNA. Proc Natl Acad Sci 99: 9133-9138. doi:10.1073/pnas.142277999

Spellman PT, Sherlock G, Zhang MQ, lyer VR, Anders K, Eisen MB, Brown PO, Botstein D, Futcher B. 1998. Comprehensive 
identification of cell cycle-regulated genes of the yeast Saccharomyces cerevisiae by microarray hybridization. Mol Biol Cell 9: 3273-3297. doi:10.1091/mbc.9.12.3273

Tafforeau L, Zorbas C, Langhendries JL, Mullineux ST, Stamatopoulou V, Mullier R, Wacheul L, Lafontaine DL. 2013. The complexity of human ribosome biogenesis revealed by systematic nucleolar screening of pre-rRNA processing factors. Mol Cell 51: 539-551. doi:10.1016/j.molcel.2013.08.011

Talkish J, Zhang J, Jakovljevic J, Horsey EW, Woolford JL Jr. 2012. Hierarchical recruitment into nascent ribosomes of assembly factors required for 27SB pre-rRNA processing in Saccharomyces cerevisiae. Nucleic Acids Res 40: 8646-8661. doi:10.1093/nar/gks609

Talkish J, Biedka S, Jakovljevic J, Zhang J, Tang L, Strahler JR, Andrews PC, Maddock JR, Woolford JL Jr. 2016. Disruption of ribosome assembly in yeast blocks cotranscriptional pre-rRNA processing and affects the global hierarchy of ribosome biogenesis. RNA 22: 852-866. doi:10.1261/rna.055780.115

Tavner FJ, Simpson R, Tashiro S, Favier D, Jenkins NA, Gilbert DJ, Copeland NG, Macmillan EM, Lutwyche J, Keough RA, et al. 1998. Molecular cloning reveals that the p160 Myb-binding protein is a novel, predominantly nucleolar protein which may play a role in transactivation by Myb. Mol Cell Biol 18: 989-1002. doi:10.1128/MCB.18.2.989

Thomas BJ, Rothstein R. 1989. Elevated recombination rates in transcriptionally active DNA. Cell 56: 619-630. doi:10.1016/00928674(89)90584-9

Thoms M, Thomson E, Bassler J, Gnädig M, Griesel S, Hurt E. 2015. The exosome is recruited to RNA substrates through specific adaptor proteins. Cell 162: 1029-1038. doi:10.1016/j.cell.2015.07.060

Thomson E, Tollervey D. 2005. Nop53p is required for late 605 ribosome subunit maturation and nuclear export in yeast. RNA 11: 1215-1224. doi:10.1261/rna.2720205

Torchet C, Hermann-Le Denmat S. 2002. High dosage of the small nucleolar RNA snR10 specifically suppresses defects of a yeast rrp5 mutant. Mol Genet Genomics 268: 70-80. doi:10.1007/s00438002-0724-z

Ulbrich C, Diepholz M, Bassler J, Kressler D, Pertschy B, Galani K, Böttcher B, Hurt E. 2009. Mechanochemical removal of ribosome biogenesis factors from nascent $60 \mathrm{~S}$ ribosomal subunits. Cell 138: 911-922. doi:10.1016/j.cell.2009.06.045

Venema J, Tollervey D. 1999. Ribosome synthesis in Saccharomyces cerevisiae. Annu Rev Genet 33: 261-311. doi:10.1146/annurev genet.33.1.261
Venema J, Planta RJ, Raué HA. 1998. In vivo mutational analysis of ribosomal RNA in Saccharomyces cerevisiae. In Protein synthesis: methods and protocols (ed. Martin R), pp. 257-270. Humana Press, Totowa, NJ.

Wade C, Shea KA, Jensen RV, McLear MA. 2001. EBP2 is a member of the yeast RRB regulon, a transcriptionally coregulated set of genes that are required for ribosome and rRNA biosynthesis. Mol Cell Biol 21: 8638-8650. doi:10.1128/MCB.21.24.8638-8650.2001

Wade $\mathrm{CH}$, Umbarger MA, McAlear MA. 2006. The budding yeast rRNA and ribosome biosynthesis (RRB) regulon contains over 200 genes. Yeast 23: 293-306. doi:10.1002/yea.1353

Wan K, Tsuchihashi K, Kanda K, Shimoji K, Mizuta K. 2013. N ${ }^{\alpha}$-acetyltransferase NatA is involved in ribosome synthesis in Saccharomyces cerevisiae. Biosci Biotechnol Biochem 77: 631638. doi:10.1271/bbb. 120860

Warner JR. 1999. The economics of ribosome biosynthesis in yeast. Trends Biochem Sci 24: 437-440. doi:10.1016/S0968-0004(99) 01460-7

Wilson DN, Doudna Cate JH. 2012. The structure and function of the eukaryotic ribosome. Cold Spring Harb Perspect Biol 4: a011536. doi:10.1101/cshperspect.a011536

Winzeler EA, Shoemaker DD, Astromoff A, Liang H, Anderson K, Andre B, Bangham R, Benito R, Boeke JD, Bussey H, et al. 1999. Functional characterization of the $S$. cerevisiae genome by gene deletion and parallel analysis. Science 285: 901-906. doi:10 $.1126 /$ science. 285.5429 .901

Woolford JL Jr., Baserga SJ. 2013. Ribosome biogenesis in the yeast Saccharomyces cerevisiae. Genetics 195: 643-681. doi:10.1534/ genetics.113.153197

Wu S, Tutuncuoglu B, Yan K, Brown H, Zhang Y, Tan D, Gamalinda M, Yuan Y, Li Z, Jakovljevic J, et al. 2016. Diverse roles of assembly factors revealed by structures of late nuclear pre-60S ribosomes. Nature 534: 133-137. doi:10.1038/nature17942

Yang W, Rogozin IB, Koonin EV. 2003. Yeast POL5 is an evolutionarily conserved regulator of rDNA transcription unrelated to any known DNA polymerases. Cell Cycle 2: 120-122. doi:10.4161/cc.2.2.329

Yusupova G, Yusupov M. 2014. High-resolution structure of the eukaryotic 80 S ribosome. Annu Rev Biochem 83: 467-486. doi:10 .1146/annurev-biochem-060713-035445

Zhang L, Wu C, Cai G, Chen S, Ye K. 2016. Stepwise and dynamic assembly of the earliest precursors of small ribosomal subunits in yeast. Genes Dev 30: 718-732. doi:10.1101/gad.274688.115 

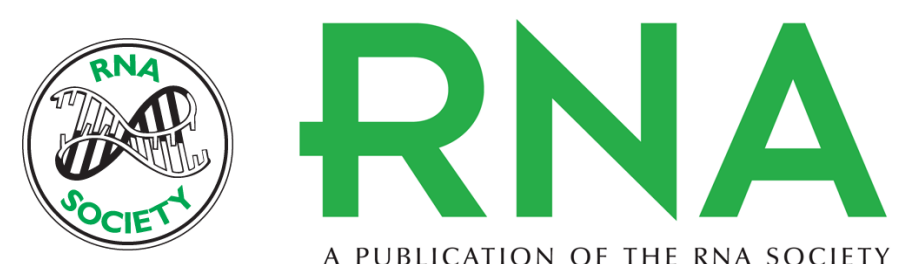

A PUBLICATION OF THE RNA SOCIETY

\section{Pol5 is an essential ribosome biogenesis factor required for 605 ribosomal subunit maturation in Saccharomyces cerevisiae}

Ana Ramos-Sáenz, Daniel González-Álvarez, Olga Rodríguez-Galán, et al.

RNA 2019 25: 1561-1575 originally published online August 14, 2019

Access the most recent version at doi:10.1261/rna.072116.119

\section{Supplemental Material}

References

Creative Commons License

Email Alerting
Service
http://rnajournal.cshlp.org/content/suppl/2019/08/14/rna.072116.119.DC1

This article cites 96 articles, 32 of which can be accessed free at: http://rnajournal.cshlp.org/content/25/11/1561.full.htmI\#ref-list-1

This article is distributed exclusively by the RNA Society for the first 12 months after the full-issue publication date (see http://rnajournal.cshlp.org/site/misc/terms.xhtml). After 12 months, it is available under a Creative Commons License (Attribution-NonCommercial 4.0 International), as described at http://creativecommons.org/licenses/by-nc/4.0/.

Receive free email alerts when new articles cite this article - sign up in the box at the top right corner of the article or click here. 